\title{
Response of bacterial community structure to different ecological niches and their functions in Korean pine forests
}

\author{
Rui-Qing Ji ${ }^{\text {Equal first author, } 1,2}$, Meng-Le Xie ${ }^{\text {Equal first author, } 2,3}{ }^{,}$Guan-Lin $\mathbf{L i}^{2}$, Yang Xu ${ }^{2}$, Ting-Ting Gao ${ }^{2}$, Peng-Jie Xing ${ }^{2}$, Li- $^{2}$ \\ Peng Meng ${ }^{\text {Corresp.. } 4}$, Shu-Yan Liu ${ }^{\text {Corresp. } 2}$ \\ 1 Jilin Agricultural University, Key Laboratory of Edible Fungus Resources Utilization in North China, Ministry of Agriculture and Rural Affairs, Changchun, \\ Jilin Province, China \\ 2 Engineering Research Center of Edible and Medicinal Fungi, Ministry of Education, Jilin Agricultural University, Changchun, Jilin Province, China \\ 3 Life Science College, Northeast Normal University, Changchun, Jili Province, China \\ ${ }^{4}$ Wood Research Institute, Jilin Forestry Science Institute, Changchun, Jilin Province, China \\ Corresponding Authors: Li-Peng Meng, Shu-Yan Liu \\ Email address: menglipengmlp@126.com, liussyan@163.com
}

A healthy plant microbiome is diverse, taxonomically structured, and gives its plant host moderate advantages in growth, development, stress tolerance, and disease resistance. The plant microbiome varies with ecological niches and is influenced by variables that are complex and difficult to separate from each other, such as the plant species, soil, and environmental factors. To explore the composition, diversity, and functions of the bacterial community of Korean pine forests, we used high-throughput sequencing to study five areas with different forest ages from June to October 2017 in northeast China. We obtained 3,247 operational taxonomic units (OTUs) based on 16S rRNA gene sequencing via an Illumina Hi-seq platform. A total of 36 phyla and 159 known genera were classified. The Shannon index of the bacterial community from the rhizospheric soil was significantly higher $(p<0.01, n=10)$ than that of the root tips. Beta-diversity analysis confirmed that the bacterial community of the rhizospheric soil was significantly different $(p<0.001)$ from the root tips. Nine bacterial phyla were dominant (relative richness $>1 \%$ ) in the rhizospheric soil, but there were six dominant phyla in the root tips. Proteobacteria was the core flora in the root tips with a relative abundance of more than $50 \%$. It is known that the formation of bacterial communities in the rhizospheric soil or the root is mainly caused by the processes of selection, and we found a relatively high abundance of a few dominant species. We further analyzed the correlations between the bacterial community from the rhizospheric soil with that of the root tips, as well as the correlations of the bacterial community with soil physicochemical properties and climate factors. We used Functional Annotation of the Prokaryotic Tax (FAPROTAX) to predict the functions of the bacterial community in the rhizospheric soil and root tips. Five related phototrophic functions, nine nitrogen cycle functions, two related chemoheterotrophic functions, and two others were predicted. The 
abundance of the bacteria phyla performing relevant functions was different in the rhizospheric soil than in the root tips. These functions were significantly influenced by the contents of nitrogen, phosphorus, and potassium in the soil habitat. The bacterial composition and functions in the rhizospheric soil and root tips of Korean pine were analyzed, and the results demonstrated the importance of soil and plant species on the bacterial community in the below ground plant microbiome. 
1 Response of bacterial community structure to different ecological 2 niches and their functions in Korean pine forests

3 Ruiqing Ji ${ }^{1,2 \#,}$ Mengle Xie ${ }^{1,3 \#,}$ Guanlin $\mathrm{Li}^{1}$, Yang Xu ${ }^{1}$, Tingting Gao ${ }^{1}$, Pengjie Xing ${ }^{1}$, Lipeng Meng ${ }^{4^{*}}$, 4 and Shuyan Liu ${ }^{1^{*}}$

$5{ }^{1}$ Engineering Research Center of Edible and Medicinal Fungi, Ministry of Education, Jilin 6 Agricultural University, Changchun, Jilin Province, P.R. China

$7 \quad{ }^{2}$ Key Laboratory of Edible Fungus Resources Utilization in North China, Ministry of Agriculture 8 and Rural Affairs, Changchun, Jilin Province, P.R. China

$9 \quad{ }^{3}$ Life Science College, Northeast Normal University, Changchun, Jilin Province, P. R. China

${ }^{4}$ Wood Research Institute, Jilin Forestry Science Institute, Changchun, Jilin Province, P.R. China

11 \#These authors have contributed equally to this work.

* Correspondence: 


\section{Abstract}

A healthy plant microbiome is diverse, taxonomically structured, and gives its plant host moderate advantages in growth, development, stress tolerance, and disease resistance. The plant microbiome varies with ecological niches and is influenced by variables that are complex and difficult to separate from each other, such as the plant species, soil, and environmental factors. To explore the composition, diversity, and functions of the bacterial community of Korean pine forests, we used high-throughput sequencing to study five areas with different forest ages from June to October 2017 in northeast China. We obtained 3,247 operational taxonomic units (OTUs) based on 16S rRNA gene sequencing via an Illumina Hi-seq platform. A total of 36 phyla and 159 known genera were classified. The Shannon index of the bacterial community from the rhizospheric soil was significantly higher $(\mathrm{p}<0.01, \mathrm{n}=10)$ than that of the root tips. Beta-diversity analysis confirmed that the bacterial community of the rhizospheric soil was significantly different $(p<0.001)$ from the root tips. Nine bacterial phyla were dominant (relative richness $>1 \%$ ) in the rhizospheric soil, but there were six dominant phyla in the root tips. Proteobacteria was the core flora in the root tips with a relative abundance of more than $50 \%$. It is known that the formation of bacterial communities in the rhizospheric soil or the root is mainly caused by the processes of selection, and we found a relatively high abundance of a few dominant species. We further analyzed the correlations between the bacterial community from the rhizospheric soil with that of the root tips, as well as the correlations of the bacterial community with soil physicochemical properties and climate factors. We used Functional Annotation of the Prokaryotic Tax (FAPROTAX) to predict the functions of the bacterial community in the rhizospheric soil and root tips. Five related phototrophic functions, nine nitrogen cycle functions, two related chemoheterotrophic functions, and two others were predicted. The abundance of the bacteria phyla performing relevant functions was different in the rhizospheric soil than in the root tips. These functions were significantly influenced by the contents of nitrogen, phosphorus, and potassium in the soil habitat. The bacterial composition and functions in the rhizospheric soil and root tips of Korean pine were analyzed, and the results demonstrated the importance of soil and plant species on the bacterial community in the below ground plant microbiome.

\section{1 | INTRODUCTION}

The root microbiome is one of the richest microbial ecosystems on earth, and bacteria are able to modulate plant growth and development (Tringe et al., 2005; Hardoim et al., 2008; Weyens et al., 2009). Using high-throughput sequencing technology, we can develop a better understanding of bacterial community composition in plants across different ecological niches, including the rhizosphere, roots, and leaves (Bulgarelli et al., 2013; Reinhold-Hurek et al., 2015; Müller et al., 2016). Studies on Arabidopsis thaliana and some crop plants in which plant root exudates drive rhizospheric microbial composition have increased our understanding of the species composition of plant-associated microbial communities and their mechanisms (Bodenhausen et al., 2014; OfekLalzar et al., 2014; Schlaeppi et al., 2014; Bai et al., 2015; Bulgarelli et al., 2015; Edwards et al., 2015; Lebeis et al., 2015; De Souza et al., 2016). The microbiome consists of fungi, bacteria, 
archaea, and oomycetes; possesses key ecological functions in forest ecological systems; and are usually well-adapted to a genotype of tree species (Bonito et al., 2019; Stephanie et al., 2021). Additionally, it is widely believed that climate factors and soil physicochemical characteristics significantly influence the soil microbiome, including soil organic matter content (Fierer et al., 2003), soil pH (Chu et al., 2010; Hu et al., 2013), air temperature (Song et al., 2016), and precipitation (Wang et al., 2015, Wang et al., 2017). We also understand that geographic distance and climate significantly shape the diversity patterns compared with soil organic matter from the large-scale biogeographical patterns of bacteria across forests (Shay et al., 2015; Tu et al., 2016; Tian et al., 2017; Walters et al., 2018). However, microbial distribution and assembly processes in micro-scale environments, such as root systems (rhizoplane and endosphere) and rhizospheric soils, are poorly understood. There is relatively little known regarding the properties of these hostassociated communities (Bulgarelli et al., 2013; Nicolitch et al., 2017; Koprivova, 2019). Therefore, in this study, we selected pure or nearly pure Korean pine forests at different ages to determine their host-associated bacterial communities and dynamic changes.

The microbial community performs a wide variety of ecological functions in different niches, such as nitrogen and carbon cycling, decomposing organic matter, and promoting the growth of plants (Kataoka \& Futai, 2009; Wu, 2012; Johannes, 2014; Kaiser et al., 2016; Wei et al., 2018). Phototrophic and chemotrophic bacteria use organic and inorganic carbon sources for their growth and development. However, they also decompose and transform organic matter in the ecosystem that is difficult to decompose in the soil, constituting an important link in the carbon cycle. Simultaneously, bacteria are important members involved in the nitrogen cycle because some bacteria can use atmospheric dinitrogen to provide the nitrogen source to most organisms that rely on bioavailable nitrogen for growth (Kuypers, 2018). Many functional prediction tools have been generated for both prokaryotic and eukaryotic microorganisms. For example, FUNGuild is a functional prediction tool for fungi that provides guild characteristics of the detected taxa (including saprotrophic, pathogenic, decomposer, or lichenivorous fungi) based on their taxonomic identity (Nguyen et al., 2016). A Phylogenetic Investigation of Communities by the Reconstruction of Unobserved States (PICRUSt) (Langille et al., 2013; Douglas et al., 2020) predicts the functional profiles from metagenomic 16S rRNA data (Tax4Fun) (Aßhauer et al., 2015; Prada-Salcedo et al., 2020), and Functional Annotation of the Prokaryotic Taxa (FAPROTAX) (Louca et al., 2016) was developed to predict bacterial and archaeal functions. FAPROTAX is the only tool that uses experimental data on culturable taxa to identify functional groups, metabolic phenotypes, or ecologically relevant functions (Louca et al., 2016). Furthermore, FAPROTAX can be used for the functional prediction of the biogeochemical cycle of environmental samples (Louca et al., 2016; Varela et al., 2018; Amit et al., 2019; Deng et al., 2019; Sansupa et al., 2021). Although FAPROTAX is unable to determine functional phenotypes of all taxa in the community, previous studies have shown that it was a helpful tool to predict functions related to biogeochemical dynamics (Sansupa et al., 2021), especially on the N and C cycles. For example, FAPROTAX was used to study the impact of microbial inoculation and fertilizer application on soil bacterial functions involved in the $\mathrm{C}$ and $\mathrm{N}$ cycles (Wang et al., 2018; 
Gao et al., 2019; Li et al., 2019). Li et al. (2019) revealed a significant effect of straw incorporation and nitrogen fertilization on hydrocarbon degradation and nitrogen fixation. Similarly, Wang et al. (2018) showed an increase of aerobic nitrite oxidation in soil inoculated with multi-species inoculants. Therefore, in this study, we selected FAPROTAX to predict bacteria functions in Korean pine root tips and rhizospheric soil.

Korean pine is a prized and ancient fossil tree species. Natural Korean pine forests are known as tertiary forests, and they have formed over hundreds of millions of years of replacement evolution (Tian, 2011). More than half of the world's Korean pines are distributed in northeast China, but their numbers have decreased with human activities, the expansion of farmland, forest area degradation, and environmental deterioration. Recently, there has been an increase in the cultivation of artificial Korean pine forests. The main issues facing Korean pine afforestation are the survival rate of seedlings and their resistance to pests and diseases (Zhang et al., 2021). However, due to unsuitable soil conditions, the survival rate of Korean pine trees is often very low (Jiang, 2016). Studies on the soil microbial composition of Korean pine forests provide a basis for selecting suitable woodland or seedling breeding bases. Ecological niches are polydimensional, and woody plants have adapted to both abiotic and biotic factors above and belowground by active or passive links. The fungal communities that inhabit the needles, buds, trunks, and branches of Korean pines change as the canopy and tree ages, and some fungal species can help the host increase its disease resistance (Song \& Huang, 2000, 2001a, 2001b, 2001c, 2001d, 2001e, 2001f). We know little about the natural microbial groups on the Korean pine root-base and how they change with different living conditions.

The objectives of this study were as follows: (1) to determine and compare the bacterial diversity and community structure of Korean pine forests across different ecological niches belowground; (2) to quantitatively assess the relative importance of multiple environmental variables (such as climate and soil physicochemical properties) in shaping bacterial diversity and community structure; (3) to quantitatively assess the relative importance of species correlations in root tips and rhizospheric soil to the community structure; and (4) to determine and compare the predicted functions across different ecological niches and their influencing factors.

\section{2 | MATERIALS AND METHODS}

\subsection{Study sites and experimental design}

This study was conducted in the main distribution areas of Korean pine in the Changbai and Xiaoxing'anling Mountains of northeast China.

To determine the bacterial community structure, ecological functions, and factors influencing bacterial community structure and functions in the rhizospheric soil and root tips, we collected samples in August at five collection plots. We collected samples from June to October at Collection site 1 (CS1: coordinates $41^{\circ} 56^{\prime} 8^{\prime \prime} \mathrm{N}, 126^{\circ} 30^{\prime} 12^{\prime \prime} \mathrm{E}$, altitude $600 \mathrm{~m}$ ) and Collection site 2 (CS2: coordinates $41^{\circ} 59^{\prime} 28^{\prime \prime} \mathrm{N}, 126^{\circ} 37^{\prime} 58^{\prime \prime} \mathrm{E}$, altitude $550 \mathrm{~m}$ ), which were pure Korean pine artificial 
forests, approximately 60 years old. Collection site 3 (CS3: coordinates $42^{\circ} 01^{\prime} 45^{\prime \prime} \mathrm{N}, 126^{\circ} 43^{\prime} 30^{\prime \prime}$ E, altitude $530 \mathrm{~m}$ ) was a 5-year-old Korean pine seedling nursery (approximately 3,000 square meters). Collection site 4 (CS4: coordinates $42^{\circ} 22^{\prime} 55^{\prime \prime} \mathrm{N}, 128^{\circ} 6^{\prime} 1^{\prime \prime} \mathrm{E}$, altitude $740 \mathrm{~m}$ ) and Collection site 5 (CS5: coordinates $47^{\circ} 11^{\prime} 4^{\prime \prime} \mathrm{N}, 128^{\circ} 52^{\prime} 52^{\prime \prime}$ E, altitude $340 \mathrm{~m}$ ) were Korean pine natural forests $>150$-year-old, with other scattered trees and shrubs. The rhizospheric soil samples and root tip samples in these five sites are labeled in Table S1.

We could easily obtain the Korean pine root tips in the pure forests. However, to ensure that the root tip samples (which were mixed with other plants to varying degrees) originated from Korean pine in the natural forests, we collected root tip samples by digging along the root system exposed on the ground to the root tips. Typically, part of the Korean pine roots stick out of the ground (Gao et al., 2020). The rhizospheric soil samples were simultaneously collected at a depth of about $20 \mathrm{~cm}$ near the Korean pine roots.

\section{2 | Sampling and processing of the root tips and rhizospheric soil}

At CS3, we dug 10 saplings each from different locations and in the center of the seedbed until we collected about 50 saplings that we then pooled together into one root tip and one rhizospheric soil composite sample. At the other collection sites, we designed four plots (20 $\mathrm{m} \times$ $20 \mathrm{~m}$, including more than five Korean pine trees) in different locations. We selected five trees from each plot and collected the fine root segments (approximately $20-50 \mathrm{~g}$ ) at four locations that were about $1 \mathrm{~m}$ from the trunk of tree (Xing et al., 2020) until we had 80 subsamples from the same collected site that we pooled into one sample. Finally, we had 10 root tip and 10 rhizosphere soil composite samples from the different sampling sites or at different sampling times for further processing.

Root tip samples from each collection site were placed in Ziplock bags and immediately maintained with dry ice. The rhizospheric soil came from the surface of the root tips. Root tip samples were soaked with sterile water and stirred with a glass stick, and the resulting soil suspension was centrifuged, its liquid discarded, and the precipitated soil was stored at $-70{ }^{\circ} \mathrm{C}$ for further analysis (Edwards et al., 2015). Root tip samples were then soaked with a solution of $0.1 \%$ Tween 20 for one hour, and then the roots were thoroughly washed with tap water. The root tip samples were covered with absorbent tissue, dried, and crushed by hand for DNA extraction (Fierer et al., 2003; Bowsher et al., 2020). The soil samples were air-dried at room temperature for determination of their physical and chemical properties.

\section{3 | Rhizospheric soil physicochemical property analyses}

The methods for analyzing the physicochemical properties of the rhizospheric soil samples followed Bao (2000). Soil available phosphorus (SAP) was determined using the $0.5 \mathrm{~mol} / \mathrm{L}$ $\mathrm{NaHCO}_{3}$ extraction-molybdenum anti-colorimetric method. Soil organic matter (SOM) was detected using the potassium dichromate volumetric method. Soil effective nitrogen (SEN) was measured using the alkali diffusion method. Soil available potassium (SAK) was determined using 
180

181

182

183

$1 \mathrm{~mol} / \mathrm{L} \mathrm{NH}_{4} \mathrm{OAC}$ extraction-flame photometry. Soil $\mathrm{pH}(\mathrm{SpH})$ was measured by potentiometry. The rainfall capacity (MR) and monthly mean air temperature (MT) during the collection process were obtained from the local weather bureau.

\section{4 | DNA extraction and Illumina sequencing}

\subsection{1 $\mid$ DNA extraction and PCR}

The total community genomic DNA of the root tip or rhizospheric soil samples was extracted using a NucleoSpin ${ }^{\circledR}$ Soillsolation Kit (MACHEREY-NAGEL, Germany) according to the manufacturer's instructions. The V3-V4 region of the $16 \mathrm{~S}$ gene was amplified using modified versions of the primer set 338F (5'-ACTCCTACGGGAGGCAGCAG-3') and 806 R (5'GGACTACHVGGGTWTCTAAT-3') (Fu et al., 2016). A PCR reaction system of $50 \mu \mathrm{L}$ was established as follows: 30 ng genomic DNA, $4 \mu \mathrm{L}$ PCR Primer Cocktail, $25 \mu \mathrm{L}$ PCR Master Mix, and $\mathrm{ddH}_{2} \mathrm{O}$ as needed. The PCR cycles were initiated using the following program: denaturation at $98^{\circ} \mathrm{C}$ for $3 \mathrm{~min}$, followed by 30 amplification cycles of $98^{\circ} \mathrm{C}$ for $45 \mathrm{~s}, 55^{\circ} \mathrm{C}$ for $45 \mathrm{~s}, 72{ }^{\circ} \mathrm{C}$ for $45 \mathrm{~s}$, and a final extension of $72{ }^{\circ} \mathrm{C}$ for $7 \mathrm{~min}$. The PCR products were purified with Ampure Xpbeads (Agencourt, Boston, MA, USA) to remove the unspecific products.

\subsection{2 | Construction library}

The qualified DNA samples were used to construct sequencing libraries. The final library was quantified in two different ways: by determining the average molecular length using an Agilent 2100 Bioanalyzer (Agilent DNA 1000 Reagents, Santa Clara, CA, USA), and quantifying the library using quantitative real-time PCR (qPCR) (EvaGreen ${ }^{\mathrm{TM}}$ ). The qualified libraries were sequenced pair-end on the system using the sequencing strategy PE250 (PE251+8+8+251) (HiSeq SBS Kit V2, Illumina, San Diego, CA, USA).

\subsection{3 | Sequencing processing}

To obtain clean reads, the raw data were filtered to eliminate the adapter pollution and low quality reads with USEARCH (v. 10.0.240) (Edgar, 2013) and UCHIME (v. 4.2.40) (Edgar et al., 2011). The paired-end reads with overlap were merged to tags. The tags were clustered to OTUs at $97 \%$ sequence similarity. The taxonomic ranks were assigned to OTU representative sequences using Ribosomal Database Project (RDP) NaïveBayesian Classifier (v. 2.2) trained on the database (Greengene_2013_5_99) and RDP database (Release 11_5, 20160930), using 0.95 confidence values as cutoff. Finally, alpha diversity and the different species screening were analyzed based

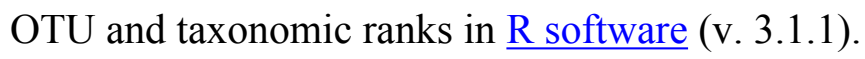

\section{5 | Data processing and statistical analyses}

Beta diversity analyses were conducted using QIIME (v. 1.80) (Caporaso et al., 2010) to evaluate the samples' differences in species complexity. Since there were differences in the sequencing depth across different samples, normalization was introduced. We used two methods to measure the beta diversity. The first was a principal coordinates analysis (PCoA) using the BrayCurtis distance, which is an index that is commonly used to reflect the differences between two 
217

218

219

220

221

222

223

224

225

226

227

228

229

230

231

232

233

234

235

236

237

238

239

240

241

242

243

244

245

246

247

248

249

250

251

communities, and its value is between zero and one. A zero Bray-Curtis value represents an exactly similar community structure. Permutational multivariate analysis of variance (PERMANOVA) was used for the difference between the groups. The second method was a cluster tree based on the Bray-Curtis distance to illustrate the distance between the bacterial species, considering the abundance of sequences. A larger index indicates greater differences between the samples. The

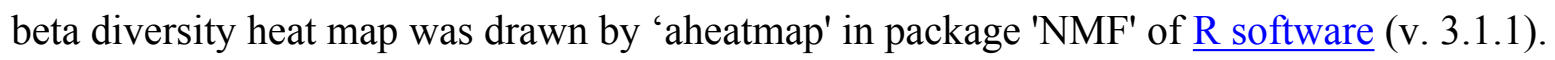

The alpha diversity was applied to analyze the complexity of species diversity for each sample through several indices, including the Shannon and Simpson indices with QIIME (v. 1.80), and

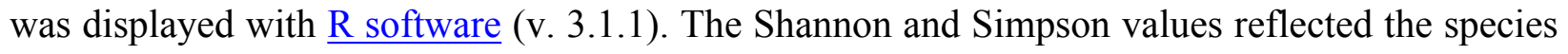
diversity of the community affected by both richness and evenness of species, i.e., the two values also considered the abundance of each species. The Simpson index was between 0 and 1, and the smaller the index value, the richer the diversity. We also used the Shannon index to explain the alpha diversity between the rhizospheric soil group and root tips group. The relative richness (RLR) of taxa was calculated to determine the dominant taxa (RLR $>1 \%$ ) across different niches.

FAPROTAX (Louca et al., 2016) is more suitable at analyzing environmental samples based on $16 \mathrm{~S}$ rDNA amplicon sequences. The database contains more than 7,600 functional annotations collected from more than 4,600 prokaryotic microorganisms in more than 80 functional groups (such as nitrate respiration, methane production, fermentation, and plant pathogens).

Moreover, Linear discriminant analysis Effect Size (LEfSe) determines the features (organisms, clades, or operational taxonomic units) most likely to explain differences between classes by coupling standard tests at a significance level of 0.05 . We conducted the analyses using LEfSe to determine the biomarker taxa in different niches. Spearman's Correlation Coefficient (Shannon et al., 2003) was used to analyze the relationship between biomarker families in root tips and all of the bacterial families of which the RLR was greater than $0.5 \%$ in their soil habitats.

The Spearman correlation analyses and redundancy analyses (RDA) were used to analyze the relationships between environmental factors and microbial diversity and composition (Clarke et al., 2014). The RDA and permutation test were conducted using the $\mathrm{R}$ (v. 3.1.1) program. $p<$ 0.05 was considered statistically significant, and $p<0.01$ was considered extremely statistically significant.

\section{3 | RESULTS}

\section{1 | Bacterial composition in Korean pine root-based diversity measures}

\subsubsection{Alpha diversity variations with ecological niches}

From June to October 2017, we generated approximately 424,170 sequences of the V3-V4 region of the 16S rRNA gene from 20 gross samples using an Illumina Hi-Seq sequencing platform. In total, we obtained 690,119 no-primer tags, and the average length was $420 \mathrm{bp}$. After 
252

253

254

255

256

257

258

259

260

261

262

263

264

265

266

267

268

the removal of the plant-derived and low-abundance OTUs, the high-quality reads were clustered into 3,247 OTUs using $\geq 97 \%$ sequence identity as the cut off. To compare the bacterial community diversity across all samples, the same survey effort level of 26,088 sequences $(75 \%$ of the sequence number of the sample with the lowest sequence number) was selected. The final statistical analysis results after 100 iterations were obtained using comprehensive statistics.

When the Shannon indices of the rhizospheric soil group and root tip group were compared, the Shannon index of the rhizospheric soil group $(6.35 \pm 0.78)$ was significantly higher than that of the root tip group $(3.56 \pm 0.27)(p<0.01, \mathrm{n}$ value=10), indicating that the bacterial species diversity of the rhizospheric soil was higher than that of the root tips (Figure 1).

\subsection{2 | Beta diversity of the rhizospheric soil and root tips}

The beta diversity was examined based on Bray-Curtis diversity distance using the principal coordinates analysis (PCoA). The first two coordinates of PCoA explained $77.17 \%$ of the variance in data $(\mathrm{PC} 1=67.98 \%, \mathrm{PC} 2=9.19 \%)$ for all the samples (Figure $2 \mathrm{a}$ ). The bacterial communities clustered into two groups by niche, the rhizospheric soil group and the root group. The results of permutational multivariate analysis of variance (PERMANOVA) by Adonis showed extremely significance difference $(p<0.001)$ of the bacterial community structure between the rhizospheric soil and root tips.

Using weighted Bray-Curtis diversity distance (Figure $2 b$ ), we clustered twenty samples into different groups: the rhizospheric soil group, CS1 (including CS1-T1, CS1-T2, CS1-T3, CS1-T4, CS1-T5, and CS1-T) and CS2 (CS2-T) were clustered into one group, CS3-T was an independent group that was different from other groups, and CS4-T and CS5-T were clustered into one group. From the results, the bacterial community from the rhizospheric soil was clustered according to different sampling plots and different tree ages. The samples in the root tips group were not grouped according to their sampling sites or the different tree ages: CS-G5 was one single branch, CS-G3 was another single branch, CS1-G2 and CS4-G were clustered into a group, and others were clustered into a group.

\subsection{Bacterial composition in the Korean pine roots based on taxonomic OTU richness}

From the samples, we obtained 3,247 bacterial OTUs that belong to 35 known phyla and one unclassified taxon, 121 classes, 221 orders, 339 families, 159 genera, and 532 species (Table S2). The number of all taxonomic grades was higher in the samples from rhizospheric soil than those from root tips.

We compared the richness of different phyla by evaluating the logarithm with base 10 of RLR (Figure 3a). From the collection site axis (the horizontal axis), two groups (rhizospheric soil and root tips) were completely separated according to the phyla RLR. The clustering of bacterial phyla from the root tips was irregular, while those from the rhizospheric soil were clustered according to forest lands. CS3-T was an independent group, CS4-T and CS5-T were clustered to the second group, and all of the rhizospheric soil samples from CS1 and CS2-T made up the third group. 
From the phyla classification axis (the vertical axis), we clustered four general branches. The RLR of WPS2, BRC1, Spirochaetes, FCPU426, GN04, GN02, GAL15, NKB19, Kazan-3B-28, Tenericutes, Fibrobacteres, FBP, and WS2 displayed lowest in rhizospheric soil and root tips. The RLR of Proteobacteria, Bacteroidetes, Actinobacteria, Acidobacteria, Verrucomicrobia, and Chloroflexi were highest in the rhizospheric soil and root tips, and almost of them in the rhizospheric soil were higher than those in the root tips except the RLR of Proteobacteria. TM7, Firmicutes, Nitrospirae, Gemmatimonadetes, Planctomycetes, and Cyanobacteria had higher RLR in rhizospheric soil and root tips, and almost all were higher in the rhizospheric soil than in the root tips except Cyanobacteria. Although the RLR of the TM6, Chlamydiae, Armatimonadetes, OD1, Elusimicrobia, WS3, Chlorobi, AD3, OP3, and unclassified taxa were lower in the rhizospheric soil and root tips, they were slightly higher in rhizospheric soil. (Figure $3 \mathrm{a}$ ).

Nine bacterial phyla (Acidobacteria, Actinobacteria, Bacteroidetes, Chloroflexi, Gemmatimonadetes, Nitrospirae, Planctomycetes, Proteobacteria, and Verrucomicrobia) were the dominant phyla in the rhizospheric soil, and six bacterial phyla (Acidobacteria, Actinobacteria, Bacteroidetes, Chloroflexi, Proteobacteria, and Verrucomicrobia) were the dominant phyla in the root tips. (Figure 3b). We compared the bacterial community biomarkers of rhizospheric soil and root tips using a cladogram. The root tip biomarkers mostly belonged to Proteobacteria, including Gammaproteobacteria, Pseudomonadales, Psudomonadaceae, Moraxellaceae, Enterobacteriaceae, Enterobacteriales, Burkholderiaceae, and Rhizobiaceae. The rhizospheric soil biomarkers belonged to Nitrospirae, Firmicutes, Bacterioidetes, Actinnobacteria, Acidobacteria, and Verrucomicrobia, and included six classes, six orders, and 10 families (Figure 3c).

\section{3 | Bacterial composition of Korean pine roots based on the predicted ecological functions}

We used FAPROTAX to predict the ecological functions of the bacterial community in the rhizospheric soil and root tip samples. We divided 18 related functions mainly into three categories: functions related to phototrophy, functions related to the nitrogen cycle, and functions related to chemoheterotrophy. The RLR of the related chemoheterotrophic functions $(30.33 \%-$ $81.19 \%$ ) in the root tips was much higher than those related to the nitrogen cycle or phototrophy. In the rhizospheric soil, the relative abundances of the three functions were uniform, while the relative abundance of those related to chemoheterotrophic functions and nitrogen cycle was slightly higher than those related to phototrophic functions.

We used cluster analysis of the logarithm with base 10 of the RLR of ecological functions and samples (Figure 4). From the collection site axis (the horizontal axis), three groups (rhizospheric soil and root tips) were completely separated, all of the rhizospheric soil was clustered into one group, the root tip samples of CS2-G and CS5-G were clustered into one group, and the rest of the root tips were clustered into another group. From the function axis (the vertical axis), two big groups were completely separated. In the first big group, the chemoheterotrophic and aerobic chemoheterotrophic RLR was higher in the rhizospheric soil and root tips, which were clustered into one subgroup. The other subgroup showed the functions of nitrate respiration, nitrate 
327

328

329

330

331

332

333

334

335

336

337

338

339

340

341

342

343

344

345

346

347

348

349

350

351

352

353

354

355

356

357

358

359

360

361

362

363

reduction, nitrogen respiration, and nitrite respiration, and the RLR from the rhizospheric soil was higher than that of the root tips. Fermentation and symbionts or animal parasites clustered into another subgroup, which showed lower RLR in the rhizospheric soil than in the root tips. In the other big group, the function of nitrogen fixation stood alone as a subgroup, and the others were in another subgroup that included phototrophic (anoxygenic photoautotrophy sulfur oxidizing, anoxygenic photoautotrophy, photoautotrophy, photoheterotrophy, and phototrophy) and some nitrogen cycle (aerobic ammonia oxidation, aerobic nitrite oxidation, nitrification, nitrate denitrification, nitrite denitrification, nitrous oxide denitrification, nitrate ammonification, and nitrite ammonification) functions.

\subsection{Climate factors, soil physicochemical properties, and the impacts on the bacterial community structure}

\subsection{1 | Climate factors and soil physicochemical properties}

The climate factors and soil physical and chemical properties across the five sampling sites are shown in Table $2 \mathrm{a} \& 2 \mathrm{~b}$. Between June and October, almost all physicochemical properties changed, except the SpH. The SEN was highest in August, SAK was significantly highest in June, and SAP and SOM were the highest in September. MR and MT were the highest in August. Based on the Spearman correlation analyses of these factors (Figure $5 a \& 5 b$ ), there were significant positive correlations between a number of factors, including the contents of SAK and $\mathrm{MR}(\mathrm{Pr}=$ 0.9, Sig. $=0.037)$, SAK and SEN $(\operatorname{Pr}=0.9$, Sig. $=0.037)$, SOM and SEN $(\operatorname{Pr}=0.9$, Sig. $=0.037)$, SOM and SpH $(\operatorname{Pr}=0.9$, Sig. $=0.037)$, MR and SAK $(\operatorname{Pr}=0.9$, Sig. $=0.037)$, and MR and MT $(\mathrm{Pr}=0.9, \mathrm{Sig} .=0.037)$. There was no significant correlation among the other factors.

The $\mathrm{SpH}$ at CS3 was higher than that of other collection sites. The $\mathrm{SpH}$ declined with forest age, while SEN, SAP, and SOM increased (Table 2b). The SAP was lowest at CS1, while the others remained stable. At CS4, it exhibited the lowest $\mathrm{pH}$ and the significantly highest SEN, SAK, SAP, and SOM. The climate factors (mean air temperature and rainfall) were different across different collection sites. Based on the Spearman correlation analyses among these factors, there were opposite correlations between $\mathrm{SpH}$ and $\mathrm{SAK}(\mathrm{Pr}=-1.0, \mathrm{Sig} .=0.037)$, MT and $\mathrm{SOM}(\mathrm{Pr}=-$ 1.0, Sig. $=0.037)$, and MR and SEN $(\operatorname{Pr}=-0.9$, Sig. $=0.037)$.

\subsubsection{Effects of soil physicochemical properties on bacterial community structure}

Samples collected from CS1 at different months showed that the SEN $(\operatorname{Pr}=0.9$, Sig. $=0.037)$ and SOM $(\mathrm{Pr}=0.9, \mathrm{Sig} .=0.037)$ had significant correlations with the Shannon index of rhizospheric soil bacteria. The $\mathrm{SpH}$ had a significantly positive correlation $(p=0.03)$ with the RLR of the dominant bacteria, and as SpH increased, the RLR of Actinobacteria, Acidobacteria, and Nitrospirae increased (Figure 6a). The SOM also had certain influence $(p=0.08)$ on the dominant bacteria RLR (Figure 6b).

In different sampling sites at different forest ages, the Shannon index of rhizospheric soil bacteria was impacted by the $\mathrm{SpH}(\operatorname{Pr}=0.9$, Sig. $=0.037), \mathrm{SEN}(\operatorname{Pr}=-0.9$, Sig. $=0.037)$, and SAK 
$364(\operatorname{Pr}=-0.9$, Sig. $=0.037)$. The SOM had a significantly positive correlation $(p=0.03)$ with the 365 dominant bacteria RLR (Figure 6c \& 6d).

\section{4. | DISCUSSION}

367

368

369

370

371

372

373

374

375

376

377

378

379

380

381

382

383

384

385

386

387

388

389

390

391

392

393

394

395

396

397

398

399

\subsection{Environmental factors determine the distribution of rhizospheric soil bacteria from Korean pine}

Although our results showed that the rhizospheric bacterial composition changed regularly with tree age and collection plots (Figure $2 \&$ Figure 3a), and that soil physical and chemical properties and climate factors were the factors affecting bacterial community structure, we could not draw conclusions due to sampling size limitations. The distribution of bacteria across different niches was driven by varying factors. In rhizospheric soil, the distribution of bacteria was correlated with the habitat, physicochemical characteristics of the habitat soil, and seasonal factors. Other studies have shown that $\mathrm{SpH}$ and $\mathrm{SOM}$ drive soil microbial communities at a global scale or in a specific region (Lauber et al., 2009; Rousk et al., 2010; Bahram et al., 2018), which confirmed our hypothesis that physicochemical properties are the most important factors affecting rhizospheric soil microbial composition and changes in the RLR of the rhizospheric soil bacteria across seasons and collection sites. For example, the RLR of Chloroflexi and Verrucomicrobia at CS3-T had positive and negative correlations with high SpH and low SEN and SAK, but we found no direct evidence for the influence of climate factors on bacterial communities. Perhaps they play an indirect role where they could influence the $\mathrm{SpH}, \mathrm{SAK}$, and SEN. At a regional scale, differences in climatic variables are quite small, which could be due to soil physical and chemical factors being the dominant factors (Bahram et al., 2018; Sun, 2020).

According to our bacterial species composition and dominant phyla results, the distribution of rhizospheric soil bacteria from Korean pine forests lands was not uniform. A few dominant species and a large number of rare species were shown. This pattern is very similar across all groups of organisms in different environmental conditions (Wang et al., 2017). Acidobacteria and Proteobacteria were the predominant phyla in the bacterial communities of other typical forests (Lauber et al., 2009; Nemergut et al., 2010; Madigan et al., 2012; Lee et al., 2018), as well as in grasslands and agricultural crop soils (Will et al., 2010; Bulgarelli et al., 2012) even though the soil conditions are very different. For example, forest soil has a higher accumulation of carbon (Blaško, 2020) and higher amounts of root exudates (Grayston et al., 1997). This may be due to the high morphological and metabolic diversity of Proteobacteria (Kersters et al., 2006) or the fact that Proteobacteria and Acidobacteria encode the genomic characteristics of high-affinity ATP transporters that cause them to be contained in various proteins (Ward et al., 2009). Therefore, the selection process determines rhizospheric soil bacteria community building in Korean pine forests, not dispersal limitations, which confirms the theory that environmental factors determine the distribution of microbial community structure, first proposed by Baas-Beeking (1934). 
400

401

402

403

404

405

406

407

408

409

410

411

412

413

414

415

416

417

418

419

420

421

422

423

424

425

426

427

428

429

430

431

432

433

434

435

436

437

438

\subsection{Root microbiota distribution of Korean pine is determined by the host's selection process}

Plant species, rhizosphere sediments, and microbial interactions are the known determinants of root-related microbiota that are distinct from the rhizospheric soil microbiota (Thiergart et al., 2020). Numerous studies have found that plants can selectively recruit microbes from the soil to establish a characteristic microbiota on their roots (Berg \& Smalla 2009; Bulgarelli et al., 2012; Edwards et al., 2015; Lebeis et al., 2015; Niu, 2017; Schlemper et al. 2017; Stringlis et al., 2018; Zhalnina et al., 2018). The bacterial phyla Proteobacteria, Firmicutes, Bacteroidetes, and Actinobacteria often make up the bacterial diversity of root microbiota (Bednarek et al., 2005; Van de Mortel et al., 2012; Kwon et al., 2016; Almario et al., 2017; Castrillo et al., 2017; Zhalnina et al., 2018). Our hypothesis that the root system of Korean pine must have its own stable microbial composition during its long life that does not change with the seasons, soil physicochemical parameters, or its age, was confirmed to some extent by our study. According to our results, the bacterial community from the Korean pine root tip samples was dominated by Proteobacteria (approximately 50\%), creating a stable bacterial community when compared with rhizospheric soil (Figures 2 \& 3). Other phyla, such as Actinobacteria, Acidobacteria, Bacteroidetes, Chloroflexi, and Verrucomicrobia, made up a smaller amount of each of the communities. The bacteria community in the Korean pine root tips were mainly the result of selection because the typical community pattern was a few dominant species and a large number of rare species.

\subsection{The bacterial community in rhizospheric soil impacts the bacterial composition of root tips}

Soil bacterial composition has the most influence on root microbial composition (Walters, 2018) and is also the bacterial reservoir for above-ground plant microbiota (Zarraonaindia et al., 2015). In different ecological districts, multiple network relationships were found among microbial species (Xiong et al., 2018, Yurgel et al., 2018). These views were confirmed by our results. Based on the results of our bacterial compositions in the rhizospheric soil and root tips, and combined with previous research, we analyzed the results of continuous sampling from June to October in the same sample site. More than $90 \%$ of OTUs of the root tip bacteria were shared with those in the rhizospheric soil habitat (Figure 7a), although the richness differed according to the PCA between the root tip and the rhizospheric soil bacteria (Figure 7b). We concluded that the bacterial composition of root tips originates from rhizospheric soil.

Mutualism, neutralism, competition, parasitism, and predation determine the composition and function of the microbial community in the ecosystem (Zengler et al., 2018). Gralka et al. (2020) stressed that trophic interactions are the drivers of microbial community assembly. Our results showed that the biomarkers of families in roots had some correlations with bacteria from the root itself and the rhizospheric soil based on the RLR of families, such as Enterobacteriacea, which displayed an extremely significant negative correlation with family OC28 $(\mathrm{r}=-0.950, p=0.007)$, and Pseudomonadaceae, which showed an extremely significant negative correlation with Nocardioidaceae $(r=-0.949, p=0.007)$ (Table S4a \& 4b). Based on our current knowledge, we 
439

440

441

442

443

444

445

446

447

448

449

450

451

452

453

454

455

456

457

458

459

460

461

462

463

464

465

466

467

468

469

470

471

472

473

474

475

cannot fully understand the relationship between different niche microorganisms, but the RLR relationship will lay the foundation for further research in these areas. A recent paper reported that the life cycle of the arbuscular mycorrhizal fungus Rhizophagus clarus could produce spores and complete its life cycle under the conditions of co-culture with Paenibacillus validus (Sachiko, 2021), which verifies the interaction between species and lays a foundation for the development of more beneficial microorganisms.

\section{4 | Bacteria functions predicted in the root tips differ from those in rhizospheric soil}

We found that the functions of bacteria are also mainly separately clustered in the rhizospheric soil and root tips, which is consistent with bacterial species composition (Figure 3a \& Figure 4). This confirmed that the bacterial functions across different niches were driven by different bacterial communities (Falkowski et al., 2008; Bai et al., 2015; Louca et al., 2016). The core phylum of Korean pine root tips is Proteobacteria, which is consistent with the abundance of chemoheterotrophy. Some bacteria genera, like Burkholderia and Rhizobium, belonged to Proteobacteria and are also known for covering 'basic' functions such as nitrogen cycling and organic matter decomposition (Lladó et al., 2018; Sobti et al., 2019). In our limited sample size, we found that the RLR of phototrophic, nitrogen, and chemoheterotrophic bacterial functions predicted in the rhizospheric soil were comparably stable with growing seasons and collection plots, but varied in the root tips. Of course, we need to further increase the sampling scale to verify these rules.

We have tried to reveal the correlations of function bacteria RLR with soil and climate factors using RDA (Figure 8 ). The first two coordinates of RDA explained only $20.67 \%$ of the variance in data $(\mathrm{RDA} 1=19.22 \%, \mathrm{PC} 2=1.45 \%)$, which illustrated that the ecological functions of bacteria were partially impacted by soil and climate factors under normal growing conditions (not extreme environment). Our results showed that the RLR of bacterial function groups in the rhizospheric soil was separated from the root tips by RDA (Figure 8a), which remain consistent with the bacterial communities. Moreover, SEN had some positive correlations with the RLR of nitrite respiration, nitrate reduction, and nitrogen respiration (Figure 8a, b), perhaps because SEN takes part in the nitrogen cycle.

\section{5 | CONCLUSION}

In this study, we found nine dominant bacterial phyla in the rhizosphere soil of Korean pine (Proteobacteria, Acidobacteria, Actinobacteria, Bacteroidetes, Chloroflexi, Verrucomicrobia, Nitrospirae, Gemmatimonadetes, and Planctomycetes) and six dominant bacterial phyla in the root tips (Proteobacteria, Acidobacteria, Actinobacteria, Bacteroidetes, Chloroflexi, and Verrucomicrobia). Proteobacteria was the core flora of the Korean pine root tips across all samples, regardless of location, age of the Korean pine forests, or date sampled. SpH, SEN, and SOM were the most significant factors that influenced the bacterial community of the rhizospheric soil. Soil origin and the plant itself were shown to be important factors driving the composition of bacterial 
476

477

478

479

480

481

482

483

484

485

486

487

488

489

490

491

492

493

494

495

496

497

498

499

500

501

502

503

504

505

506

communities in the Korean pine root tips. The interactions between bacterial families varied across different ecological niches based on the RLR and Spearman correlation analyses of the biomarker families in the root with bacterial species composition. The RLR of chemoheterotrophic bacterial functions predicted in the root tips was higher than the predictions for phototrophic and nitrogen functions. The impact of microbiome composition on the growth and health of Korean pine or other prized and ancient fossil ectomycorrhizal trees and specific ectomycorrhizal fungi, including mycorrhizal helper bacteria that could help mycorrhizal fungi navigate toward the root tips and enter the root to absorb nutrients, will be the subject of future studies.

\section{REFERENCES}

Almario J, Jeena G, Wunder J, Langen G, Zuccaro A, Coupland G, Bucher M. 2017. Rootassociated fungal microbiota of nonmycorrhizal Arabis alpina and its contribution to plant phosphorus nutrition. Proceedings of the National Academy of Sciences of the United States of America 114(44):E9403-E9412 DOI 10.1073/pnas.1710455114.

Aßhauer KP, Bernd W, Rolf D, Peter M. 2015. Tax4Fun: predicting functional profiles from metagenomic 16S rRNA data. Bioinformatics 31(17):2882-2884 DOI 10.1093/bioinformatics/btv287.

Amit K, Ng DHP, Wu Y, Cao B. 2019. Microbial community composition and putative biogeochemical functions in the sediment and water of tropical granite quarry lakes. Microbial Ecology 7(1):1-11 DOI 10.1007/s00248-018-1204-2.

Bahram M, Hildebrand F, Forslund SK, Anderson JL, Soudzilovskaia NA, Bodegom PM, Bengtsson-Palme J, Anslan S, Coelho LP, Harend H, Huerta-Cepas J, Medema MH, Maltz MR, Mundra S, Olsson PA, Pent M, Põlme S, Sunagawa S, Ryberg M, Tedersoo L, Bork P. 2018. Structure and function of the global topsoil microbiome. Nature 560(7717):233-237 DOI 10.1038/s41586-018-0386-6.

Bai Y, Mair DB, Srinivas G, Garrido-Oter R, Potthoff E, Rott M, Dombrowski N, Münch PC, Spaepen S, Remus-Emsermann M, Hüttel B, McHardy AC, Vorholt JA, SchulzeLefert P. 2015. Functional overlap of the Arabidopsis leaf and root microbiota. Nature 528(7582):364-369 DOI 10.1038/nature16192.

Bao SD. 2000. Soil agrochemical analysis. Beijing: Agricultural Press.

Bednarek P, Schneider B, Svatos A, Oldham NJ, Hahlbrock K. 2005. Structural complexity, differential response to infection, and tissue specificity of indolic and phenylpropanoid 
507

508

509

510

511

512

513

514

515

516

517

518

519

520

521

522

523

524

525

526

527

528

529

530

531

532

533

534

535

536

537

secondary metabolism in Arabidopsis roots. Plant Physiology 138(2):1058-1070 DOI 10.1104/pp.104.057794.

Berg G \& Smalla K. 2009. Plant species and soil type cooperatively shape the structure and function of microbial communities in the rhizosphere. FEMS Microbiology Ecology 68(1):113 DOI 10.1111/j.1574-6941.2009.00654.x.

Blado R, Forsmark B, Gundale MJ, Lundmark T, Nordin A. 2020. Impacts of tree species identity and species mixing on ecosystem carbon and nitrogen stocks in a boreal forest. Forest Ecology and Management 458:117783 DOI 10.1016/j.foreco.2019.117783.

Bodenhausen N, Bortfeld-Miller M, Ackermann M, Vorholt JA. 2014. A synthetic community approach reveals plant genotypes affecting the phyllosphere microbiota. PLoS Genetics 10(4):e1004283 DOI 10.1371/journal.pgen.1004283.

Bonito G, Benucci GMN, Hameed K, Weighill D, Jones P, Chen K-H, Jacobson D, Schadt C, Vilgalys R. 2019. Fungal-Bacterial networks in the Populus rhizobiome are impacted by soil properties and host genotype. Frontiers in Microbiology 10:481 DOI 10.3389/fmicb.2019.00481.

Bowsher AW, Benucci GMN, Bonito G, Shade A 2020. Seasonal dynamics of core fungi in the switchgrass phyllosphere, and co-occurrence with leaf bacteria. Phytobiomes Journal 5(1):60-68 DOI 10.1094/PBIOMES-07-20-0051-R.

Bulgarelli D, Garrido-Oter R, Münch PC, Weiman A, Dröge J, Pan Y, McHardy AC, Schulze-Lefert P. 2015. Structure and function of the bacterial root microbiota in wild and domesticated barley. Cell Host \& Microbe 17(3):392-403 DOI 10.1016/j.chom.2015.01.011.

Bulgarelli D, Rott M, Schlaeppi K, van Themaat EVL, Ahmadinejad N, Assenza F, Rauf P, Huettel B, Reinhardt R, Schmelzer E, Peplies J, Gloeckner FO, Amann R, Eickhorst T, Schulze-Lefert P. 2012. Revealing structure and assembly cues for Arabidopsis rootinhabiting bacterial microbiota. Nature 488(7409):91-95 DOI 10.1038/nature11336.

Bulgarelli D, Schlaeppi K, Spaepen S, van Themaat EVL, Schulze-Lefert P. 2013. Structure and functions of the bacterial microbiota of plants. Annual Review of Plant Biology 64:807838 DOI 10.1146/annurev-arplant-050312-120106.

Caporaso JG, Kuczynski J, Stombaugh J, Bittinger K, Bushman FD, Costello EK, Fierer N, Peña AG, Goodrich JK, Gordon JI, Huttley GA, Kelley ST, Knights D, Koenig JE, Ley RE, Lozupone CA, McDonald D, Muegge BD, Pirrung M, Reeder J, Sevinsky JR, 
Turnbaugh PJ, Walters WA, Widmann J, Yatsunenko T, Zaneveld J, Knight R. 2010. QIIME allows analysis of high-throughput community sequencing data. Nature Methods 7(5):335-336 DOI 10.1038/nmeth.f.303.

Castrillo G, Teixeira PJPL, Paredes SH, Law TF, de Lorenzo L, Feltcher ME, Finkel OM, Breakfield NW, Mieczkowski P, Jones CD, Paz-Ares J, Dangl JL. 2017. Root microbiota drive direct integration of phosphate stress and immunity. Nature 543(7646): 513-518. doi 10.1038 /nature21417.

Chu H, Fierer N, Lauber CL, Caporaso JG, Knight R, Grogan P. 2010. Soil bacterial diversity in the arctic is not fundamentally different from that found in other biomes. Environmental Microbiology 12(11):2998-3006 DOI 10.1111/j.1462-2920.2010.02277.x.

Clarke SF, Murphy EF, O'Sullivan O, Lucey AJ, Humphreys M, Hogan A, Hayes P, O'Reilly M, Jeffery IB, Wood-Martin R, Kerins DM, Quigley E, Ross RP, O'Toole PW, Molloy MG, Falvey E, Shanahan F, Cotter PD. 2014. Exercise and associated dietary extremes impact on gut microbial diversity. Gut 63(12):1913-1920 DOI 10.1136/gutjnl-2013-306541.

De Souza RSC, Okura VK, Armanhi JSL, Armanhi JSL, Jorrza R, Lozano N, da Silva MJ, González-Guerrero M, de Araújo LM, Verza NC, Bagheri HC, Imperial J, Arruda P. 2016. Unlocking the bacterial and fungal communities assemblages of sugarcane microbiome. Scientific Reports 6:28774 DOI 10.1038/srep28774.

Deng J, Zhang Y, Yin Y, Zhu X, Zhu W, Zhou Y. 2019. Comparison of soil bacterial community and functional characteristics following afforestation in the Semi-Arid areas. PeerJ 7:e7141 DOI $10.7717 /$ peerj. 7141.

Douglas GM, Maffei VJ, Zaneveld J, Yurgel SN, Brown JR, Taylor CM, Huttenhower C, Langille MGI. 2020. PICRUSt2: An improved and customizable approach for metagenome inference. bioRxiv 672295 DOI 10.1101/672295.

Edgar RC. 2013. UPARSE: Highly accurate OTU sequences from microbial amplicon reads. Nature Methods 10(10):996-998 DOI 10.1038/NMETH.2604.

Edgar RC, Haas BJ, Clemente JC, Quince C, Knight R. 2011. UCHIME improves sensitivity and speed of chimera detection. Bioinformatics 27(16):2194-2200 DOI 10.1093/bioinformatics/btr381.

Edwards J, Johnson C, Santos-Medellrd C, Lurie E, Podishetty NK, Bhatnagar S, Eisen JA, Sundaresan V. 2015. Structure, variation, and assembly of the root-associated microbiomes 
569

570

571

572

573

574

575

576

577

578

579

580

581

582

583

584

585

586

587

588

589

590

591

592

593

594

595

596

597

598

599

600

of rice. Proceedings of the National Academy of Sciences of the United States of America 112(8):E911-E920 DOI 10.1073/pnas.1414592112.

Falkowski PG, Fenchel T, Delong EF. 2008. The microbial engines that drive earth's biogeochemical cycles. Science 320(5879):1034-1039 DOI 10.1126/science.1153213.

Fierer N, Holden JPSA 2003. Influence of drying-rewetting frequency on soil bacterial community structure. Microbial Ecology 45(1):63-71 DOI 10.1007/s00248-002-1007-2.

Fierer N, Schimel JP, Holden PA. 2003. Variations in microbial community composition through two soil depth profiles. Soil Biology \& Biochemistry 35(1):167-176 DOI 10.1016/S00380717(02)00251-1.

Fu J, Lv H, Feng C. 2016. Diversity and variation of bacterial community revealed by miseq sequencing in Chinese dark teas. PLoS One 11(9):e0162719 DOI 10.1371/journal.pone.0162719.

Gao GF, Li PF, Zhong JX, Shen ZJ, Chen J, Li YT, Isabwe A, Zhu XY, Ding QS, Zhang S, Gao CH, Zheng HL. 2019. Spartina alterniflora invasion alters soil bacterial communities and enhances soil $\mathrm{N}_{2} \mathrm{O}$ emissions by stimulating soil denitrification in mangrove wetland. Science of the Total Environment 653:231-240 DOI 10.1016/j.scitotenv.2018.10.277.

Gralka M, Szabo R, Stocker R, Cordero OX. 2020. Trophic interactions and the drivers of microbial community assembly. Current Biology 30(19):R1176-R1188 DOI 10.1016/j.cub.2020.08.007.

Grayston SJ, Vaughan D, Jones D. 1997. Rhizosphere carbon flow in trees, in comparison with annual plants: the importance of root exudation and its impact on microbial activity and nutrient availability. Applied Soil Ecology 5(1):29-56 DOI 10.1016/S0929-1393(96)001266.

Hardoim PR, van Overbeek LS, Elsas JD. 2008. Properties of bacterial endophytes and their proposed role in plant growth. Trends in Microbiology 16(10):463-471 DOI 10.1016/j.tim.2008.07.008.

Hereira-Pacheco SE, Navarro-Noya YE, Dendooven L. 2021. The root endophytic bacterial community of Ricinus communis L. resembles the seeds community more than the rhizosphere bacteria independent of soil water content. Scientific Reports 11(1):2173 DOI 10.1038/s41598-021-81551-7.

Hu HW, Zhang LM, Dai Y, Di HJ, He JZ. 2013. pH-dependent distribution of soil ammonia oxidizers across a large geographical scale as revealed by high-throughput pyrosequencing.

Peer] reviewing PDF | (2021:06:62999:3:0:NEW 29 Jan 2022) 
602

603

604

605

606

607

608

609

610

611

612

613

614

615

616

617

618

619

620

621

622

623

624

625

626

627

628

629

630

Johannes R \& Per B. 2014. Microbial regulation of global biogeochemical cycles. Frontiers in Microbiology 5:103 DOI 10.3389/fmicb.2014.00103.

Kaiser K, Wemheuer B, Korolkow V, Wemheuer F, Nacke H, Schöning I, Schrumpf M, Daniel R. 2016. Driving forces of soil bacterial community structure, diversity, and function in temperate grasslands and forests. Scientific Reports 6:33696 DOI 10.1038/srep33696.

Kataoka R \& Futai K. 2009. A new mycorrhizal helper bacterium, ralstonia species, in the ectomycorrhizal symbiosis between Pinus thunbergii and Suillus granulatus. Biology and Fertility of Soils 45:315-320 DOI 10.1007/s00374-008-0340-0.

Kersters K, Vos PD, Gillis M, Swings J, Stackebrandt E. 2006. Introduction to the Proteobacteria. New York: Springer.

Koprivova A, Schuck S, Jacoby RP, Klikhammer I, Welter B, Leson L, Martyn A, Nauen J, Grabenhorst N, Mandelkow JF, Zuccaro A, Zeier J, Kopriva S. 2019. Root-specific camalexin biosynthesis controls the plant growth promoting effects of multiple bacterial strains. Proceedings of the National Academy of Sciences of the United States of America 116(31):15735-15744 DOI 10.1073/pnas.1818604116.

Kuypers M, Marchant H, Kartal B. 2018. The microbial nitrogen-cycling network. Nature Reviews Microbiology 16(5):263-276 DOI 10.1038/nrmicro.2018.9.

Kwon YS, Lee DY, Rakwal R, Baek SB, Lee JH, Kwak YS, Seo J-S, Chung WS, Bae D-W, Kim SG. 2016. Proteomic analyses of the interaction between the plant-growth promoting rhizobacterium Paenibacillus polymyxa E681 and Arabidopsis thaliana. Proteomics 16(1):122-135 DOI 10.1002/pmic.201500196.

Langille MGI, Zaneveld J, Caporaso JG, Mcdonald D, Knights D, Reyes JA, Clemente JC, Burkepile DE, Thurber RLV, Knight R, Beiko RG, Huttenhower C. 2013. Predictive functional profiling of microbial communities using 16S rRNA marker gene sequences. Nature Biotechnology 31(9):814-821 DOI 10.1038/nbt.2676.

Lauber CL, Hamady M, Knight R, Fierer N. 2009. Pyrosequencing-based assessment of soil $\mathrm{pH}$ as a predictor of soil bacterial community structure at the continental scale. Applied and Environmental Microbiology 75(15):5111-5120 DOI 10.1128/AEM.00335-09.

Lebeis SL, Paredes SH, Lundberg DS, Breakfield N, Gehring J, Mcdonald M, Malfatti S, del 
631

632

633

634

635

636

637

638

639

640

641

642

643

644

645

646

647

648

649

650

651

652

653

654

655

656

657

658

659

660

Rio TG, Jones CD, Tringe SG, Dangl JL. 2015. Salicylic acid modulates colonization of the root microbiome by specific bacterial taxa. Science 349(6250):860-864 DOI 10.1126/science.aaa8764.

Lee BJ \& Eo SH. 2018. Metagenomic approach revealed effects of forest thinning on bacterial communities in the forest soil of Mt. Janggunbong, South Korea. Journal of Mountain Science 15:59-67 DOI 10.1007/s11629-017-4428-6.

Li H, Zhang YY, Yang S, Wang ZR, Feng X, Liu HY, Jiang Y. 2019. Variations in soil bacterial taxonomic profiles and putative functions in response to straw incorporation combined with $\mathrm{N}$ fertilization during the maize growing season. Agriculture Ecosystems \& Environment 283:106578 DOI 10.1016/j.agee.2019.106578.

Lladó S, Lopez-Mondejar R, Baldrian P. 2018. Drivers of microbial community structure in forest soils. Applied Microbiology and Biotechnology 102(10):4331-4338 DOI 10.1007/s00253-018-8950-4.

Louca S, Parfrey LW, Doebeli M. 2016. Decoupling function and taxonomy in the global ocean microbiome. Science 353(6305):1272-1277 DOI 10.1126/science.aaf4507.

Madigan M, Martinko J, Stahl D, Clark D. 2012. Brock Biology of Microorganisms. San Francisco: Pearson Education.

Müller DB, Vogel C, Bai Y, Vorholt JA. 2016. The plant microbiota: systems-level insights and perspectives. Annual Review of Genetics 50:211-234 DOI 10.1146/annurev-genet-120215034952 .

Nemergut DR, Cleveland CC, Wieder WR, Washenberger CL, Townsend AR. 2010. Plotscale manipulations of organic matter inputs to soils correlate with shifts in microbial community composition in a lowland tropical rain forest. Soil Biology \& Biochemistry 42(12):2153-2160 DOI 10.1016/j.soilbio.2010.08.011.

Nguyen NH, Song ZW, Bates ST, Branco S, Tedersoo L, Menke J, Schilling JS, Kennedy PG. 2016. FUNGuild: An open annotation tool for parsing fungal community datasets by ecological guild. Fungal Ecology 20: 241-248 DOI: 10.1016/j.funeco.2015.06.006.

Nicolitch O, Turpault MP, Faucher L, Uroz S. 2017. Tree roots select specific bacterial communities in the subsurface critical zone. Soil Biology \& Biochemistry 115:109-123 DOI 10.1016/j.soilbio.2017.07.003. 
661

662

663

664

665

666

667

668

669

670

671

672

673

674

675

676

677

678

679

680

681

682

683

684

685

686

687

688

689

690

691

Niu B, Paulson JN, Zheng XQ, Kolter R. 2017. Simplified and representative bacterial community of maize roots. Proceedings of the National Academy of Sciences of the United States of America 114(12):E2450-E2459 DOI 10.1073/pnas.1616148114.

Ofek-Lalzar M, Sela N, Goldman-Voronov M, Green SJ, Hadar Y, Minz D. 2014. Niche and host-associated functional signatures of the root surface microbiome. Nature Communications 5:4950 DOI 10.1038/ncomms5950.

Prada-Salcedo LD, Wambsgan J, Bauhus J, Buscot F, Goldmann K. 2020. Low root functional dispersion enhances functionality of plant growth by influencing bacteria activities in European forest soils. Environmental Microbiology 23(4):1889-1906 DOI 10.1111/14622920.15244.

Reinhold-Hurek B, Bünger W, Burbano CS, Sabale M, Hurek T. 2015. Roots shaping their microbiome: global hotspots for microbial activity. Annual Review of Phytopathology 53:403-424 DOI 10.1146/annurev-phyto-082712-102342.

Rousk J, Baath E, Brookes PC, Lauber CL, Lozupone C, Caporaso JG, Knight R, Fierer N. 2010. Soil bacterial and fungal communities across a $\mathrm{pH}$ gradient in an arablesoil. ISME Journal 4(10): 1340-1351 DOI 10.1038/ismej.2010.58.

Sachiko T, Kay H, Yuuki K, Koji Y, Taro M, Hiromu K, Tatsuhiro E, Katsuharu S, Kohki A, Masayoshi K. 2021. Asymbiotic mass production of the arbuscular mycorrhizal fungus Rhizophagus clarus. bioRxiv 2020.12.25.424379 DOI 10.1101/2020.12.25.424379.

Sansupa C, Fareed S, Wahdan M, Hossen S, Purahong W. 2021. Can we use functional annotation of prokaryotic taxa (FAPROTAX) to assign the ecological functions of soil bacteria? Applied Sciences 11(2):688 DOI 10.3390/app11020688.

Schlaeppi K, Dombrowski N, Oter RG, van Themaat EV, Schulze-Lefert P. 2014. Quantitative divergence of the bacterial root microbiota in Arabidopsis thaliana relatives. Proceedings of the National Academy of Sciences of the United States of America 111(2):585-592 DOI 10.1073/pnas.1321597111.

Schlemper TR, Leite MFA, Lucheta AR, Shimels M, Bouwmeester H., van Veen JA, Kuramae EE. 2017. Rhizobacterial community structure differences among sorghum cultivars in different growth stages and soils. FEMS Microbiology Ecology 93(8):1-11 DOI 10.1093/femsec/fix096.

Shannon P, Markiel A, Ozier O, Baliga NS, Wang JT, Ramage D, Amin N, Schwikowski B, 
692

693

694

695

696

697

698

699

700

701

702

703

704

705

706

707

708

709

710

711

712

713

714

715

716

717

Ideker T. 2003. Cytoscape: a software environment for integrated models of biomolecular interaction networks. Genome Research 13(11):2498-2504 DOI 10.1101/gr.1239303.

Shay PE, Winder RS, Trofymow J. 2015. Nutrient-cycling microbes in coastal douglas-fir forests: regional-scale correlation between communities, in situ climate, and other factors. Frontiers in Microbiology, 6:1097 DOI 10.3389/fmicb.2015.01097.

Sobti RC, Arora NK, Kothari R. 2019. In Environmental Biotechnology: For Sustainable Future. New York: Springer.

Song G, Hou J, Li Y, Zhang JH, He NP. 2016. Leaf caloric value from tropical to cold-temperate forests: latitudinal patterns and linkage to productivity. PLoS One 11(6): e0157935 DOI 10.1371/journal.pone.0157935.

Song RQ \& Huang YQ. 2000. Dendrocola fungi on Korean pine and important diseases caused by dendrocola fungi. Journal of Northeast Forestry University 28:64-67 DOI 10.13759/j.cnki.dlxb.2000.03.017.

Song RQ \& Huang YQ. 2001a. Dendrocola mycoflora of buds on Korean pine I . Journal of Northeast Forestry University, 29:98-102 DOI 10.13759/j.cnki.dlxb.2001.01.028.

Song RQ \& Huang YQ. 2001b. Dendrocola mycoflora of needles on Korean pine II . Journal of Northeast Forestry University 29:103-107 DOI 10.13759/j.cnki.dlxb.2001.01.029.

Song RQ \& Huang YQ. 2001c. Dendrocola mycoflora of branches on Korean pine III. Journal of Northeast Forestry University 29:108-114 DOI 10.13759/j.cnki.dlxb.2001.01.030.

Song RQ \& Huang YQ. 2001d. Dendrocola Mycoflora of stems on Korean pine IV. Journal of Northeast Forestry University 29:115-117 DOI 10.13759/j.cnki.dlxb.2001.01.031

Song RQ \& Huang YQ. 2001e. Distributed patterns of dendrocola mycoflora on Korean pine V. Journal of Northeast Forestry University 29:118-122 DOI 10.13759/j.cnki.dlxb.2001.01.032.

Song RQ \& Huang YQ. 2001f. The relationship between the species diversity of dendrocola mycoflora on Korean pine and disease VI. Journal of Northeast Forestry University 29:123- 
125 DOI 10.13759/j.cnki.dlxb.2001.01.033.

Stringlis IA, Ke Y, Feussner K, de Jonge R, van Bentum S, van Verk MC, Berendsen RL, Bakker PAHM, Feussner I, Pieterse CMJ 2018. MYB72-dependent coumarin exudation shapes root microbiome assembly to promote plant health. Proceedings of the National Academy of Sciences of the United States of America 115(22): E5213-E5222 DOI 10.1073/pnas.1722335115.

Sun YT. 2020. Study on the geographical distribution and driving mechanism of forest soil bacterial community in China. PhD. Thesis, University of Chinese Academy of Sciences.

Thiergart T, Durán P, Ellis T, Vannier N, Garrido-Oter R, Kemen E, Roux F, Alonso-Blanco C, Ågren J, Schulze-Lefert P, Hacquard S. 2020. Root microbiota assembly and adaptive differentiation among european Arabidopsis populations. Nature Ecology \& Evolution 4(1):122-131 DOI 10.1038/s41559-019-1063-3.

Tian FF. 2011. Analysis of molelecular natural Pinus koraiensis based on Nad5 mitochondrial DNA sequence. Master thesis, Liaoning Normal University.

Tian J, He NP, Hale L, Niu SL, Yu GR, Liu Y, Blagodatskaya E, Kuzyakov Y, Gao Q, Zhou JZ. 2017. Soil organic matter availability and climate drive latitudinal patterns in bacterial diversity from tropical to cold-temperate forests. Functional Ecology 32(1):61-70 DOI $10.1111 / 1365-2435.12952$.

Tringe SG, Mering CV, Kobayashi A, Salamov AA, Chen K, Chang HW, Podar M, Short JM, Mathur EJ, Detter JC, Bork P, Hugenholtz P, Rubin EM. 2005. Comparative metagenomics of microbial communities. Science 308(5721):554-557 DOI 10.1126/science.1107851.

Tu Q, Deng Y, Yan Q, Shen LN, Lin L, He ZL, Wu LY, Van Nostrand JD, Buzzard V, Michaletz ST, Enquist BJ, Weiser MD, Kaspari M, Waide RB, Brown JH, Zhou JZ. 2016. Biogeographic patterns of soil diazotrophic communities across six forests in the North America. Molecular Ecology 25(12):2937-2948 DOI 10.1111/mec.13651.

Van de Mortel JE, de Vos RCH, Dekkers E, Pineda A, Guillod L, Bouwmeester K, van Loon JJA, Dicke M, Raaijmakers JM. 2012. Metabolic and transcriptomic changes induced in Arabidopsis by the rhizobacterium Pseudomonas fluorescens SS101. Plant Physiology 160(4):2173-2188 DOI 10.1104/pp.112.207324.

Varela BJ, Lesbarrères D, Ibáñez R, Green DM. 2018. Environmental and host effects on skin 
749

750

751

752

753

754

755

756

757

758

759

760

761

762

763

764

765

766

767

768

769

770

771

772

773

774

775

776

777

778

779

bacterial community composition in Panamanian frogs. Frontiers in Microbiology 9:298 DOI 10.3389/fmicb.2018.00298.

Walters WA, Jin Z, Youngblut N, Wallace JG, Sutter J, Zhang W, González-Peña A, Peiffer J, Koren O, Shi QJ, Knight R, del Rio TG, Tringe SG, Buckler ES, Dangl JL, Ley RE. 2018. Large-scale replicated field study of maize rhizosphere identifies heritable microbes. Proceedings of the National Academy of Sciences of the United States of America 115(28):7368-7373 DOI 10.1073/pnas.1800918115.

Wang JJ, Li QQ, Xu S, Zhao W, Lei Y, Song CH, Huang ZY. 2018. Traits-Based Integration of Multi-Species Inoculants Facilitates Shifts of Indigenous Soil Bacterial Community. Frontiers in Microbiology 9:1692 DOI 10.3389/fmicb.2018.01692.

Wang NN, Han DX, Sun X, Guo W, Ma HY, Feng FJ. 2017. Effects of precipitation change on soil microbial functional diversity in the primitive Korean pine and broadleaved forests. Acta Ecologica Sinica 37(03):868-876 DOI 10.5846/stxb201509101873.

Wang RL, Yu GR, He NP, Wang QF, Zhao N, Xu ZW. 2015. Latitudinal patterns and influencing factors of leaf functional traits in Chinese forest ecosystems. Acta Geographica Sinica 70(11):1735-1746 DOI 10.11821/dlxb201511004.

Wang XB, Lv XT, Yao J, Wang ZW, Deng Y, Cheng WX, Zhou JZ, Han XG. 2017. Habitatspecific patterns and drivers of bacterial $\beta$-diversity in China's drylands. ISME Journal 11(6):1345-1358 DOI 10.1038/ismej.2017.11.

Ward NL, Challacombe JF, Janssen PH, Henrissat B, Kuske CR. 2009. Three genomes from the phylum acidobacteria provide insight into the lifestyles of these microorganisms in soils. Applied and Environmental Microbiology 75(7):2046-2056 DOI 10.1128/AEM.02294-08.

Wei H, Peng CH, Yang B, Song HX, Li Q, Jiang L, Wei G, Wang KF, Wang H, Liu SR, Liu XJ, Chen DX, Li YD, Wang M. 2018. Contrasting soil bacterial community, diversity, and function in two forests in China. Frontiers in Microbiology 9:1693 DOI 10.3389/fmicb.2018.01693.

Weyens N, van der Lelie D, Taghavi S, Vangronsveld J. 2009. Phytoremediation: plantendophyte partnerships take the challenge. Current Opinion in Biotechnology 20(2):248-254 DOI 10.1016/j.copbio.2009.02.012.

Will C, Thürmer A, Wollherr A, Nacke H, Herold N, Schrumpf M, Gutknecht J, Wubet T, Buscot F, Daniel R. 2010. Horizon-specific bacterial community composition of German 
780

781

782

783

784

785

786

787

788

789

790

grassland soils, as revealed by pyrosequencing-based analysis of 16S rRNA genes. Applied and Environmental Microbiology 76(20):6751-6759. DOI 10.1128/AEM.01063-10.

Wu XQ, Hou LL, Sheng JM, Ren JH, Zheng L, Chen D, Ye JR. 2012. Effects of ectomycorrhizal fungus Boletus edulis and mycorrhiza helper Bacillus cereus on the growth and nutrient uptake by Pinus thunbergii. Biology and Fertility of Soils 48:385-391 DOI 10.1007/s00374-011-0638-1.

Xing PJ, Xu Y, Gao TT, Li GL, Zhou JJ, Xie ML, Ji RQ. 2020. The community composition variation of Russulaceae associated with the Quercus mongolica forest during the growing season at Wudalianchi City, China. PeerJ 8:e8527 DOI 10.7717/peerj.8527.

Xiong W, Jousset A, Guo S, Karlsson I, Zhao QY, Wu HS, Kowalchuk GA, Shen QR, Li R, Geisen S. 2018. Soil protist communities form a dynamic hub in the soil microbiome. ISME Journal 12(2):634-638. DOI 10.1038/ismej.2017.171.

Yin H, Liu HB, Guo PW, Hans L. 2009. An analysis on the climatic response mechanism of the growth of Pinus koraiensis in the lower mountains of XiaoXing'AnLing. Acta Ecologica Sinica 29(12): 6333-6341 DOI: 10.1016/1047-2797(92)90031-K.

Yurgel SN, Douglas GM, Dusault A, Percival D, Langille MGI. 2018. Dissecting community structure in wild blueberry root and soil microbiome. Frontiers in Microbiology 9:1187 DOI 10.3389/fmicb.2018.01187.

Zarraonaindia I, Owens SM, Weisenhorn P, West K, Hampton-Marcell J, Lax S, Bokulich NA, Mills DA, Martin G, Taghavi S, van der Lelie D, Gilbert JA. 2015. The soil microbiome influences grapevine-associated microbiota. mBio 6(2):e02527-14 DOI 10.1128/mBio.02527-14.

Zengler K, Zaramela LS. 2018. The social network of microorganisms - how auxotrophies shape complex communities. Nature Reviews Microbiology 16(6):383-390 DOI 10.1038/s41579-018-0004-5.

Zhalnina K, Louie KB, Zhao H, Mansoori N, da Rocha UN, Shi SJ, Cho H, Karaoz U, Loqué D, Bowen BP, Firestone MK, Northen TR, Brodie EL. 2018. Dynamic root exudate chemistry and microbial substrate prefer- ences drive patterns in rhizosphere microbial community assembly. Nature Microbiology 3(4):470-480 DOI 10.1038/s41564-018-0129-3.

Zhang P, Xie GQ, Tian Z, Liu ZH, Wang LH. 2021. Relationship between ecological biomes and Armillaria ostoyae root rot disease of Pinus koraiensis plantation. Journal of Central 
811

812

813

814

815

816

817

818

819

820

821

822

823

824

825

826

827

828

829

830

831

832

833

834

835

6

South University of Forestry \& Technology 41(3):54-63 DOI 10.14067/j.cnki.1673$923 x .2021 .03 .007$.

Legends:

Table 1. Bacteria alpha diversity

(a) Collection site 1 from June to October 2017. (b) Different collection sites in August 2017.

\section{Table 2. Soil physical and chemical properties}

(a) Collection site 1 from June to October 2017. (b) Different collection sites in August 2017.

Figure 1. Shannon index boxplot of bacterial communities between the rhizospheric soil and the root tips.

Figure 2. Beta diversity responded to the bacterial community of the rhizospheric soil and the root tips

(a) Principal coordinates analysis $(\mathrm{PCoA})$ based on Bray-Curtis distance $(\mathrm{P}<0.001$, permutational multivariate analysis of variance (PERMANOVA) by Adonis); (b) Heat map based on Bray-Curtis distance.

\section{Figure 3. The bacterial composition of the rhizospheric soil and the root tips based on taxonomic OTU} richness

\footnotetext{
(a) Log-scaled percentage heat map of phylum-level; (b) The bacterial dominant Phyla in different collection sites (the relative richness $>0.01 \%$ ); (c) The biomarker in root tips and in rhizospheric soil of Korean pine forest by LEfSe.
}

Figure 4. Log-scaled percentage heatmap of bacterial functions predicted in different samples.

Figure 5. Heatmap showed the correlation of soil physical and chemical properties 
836

837

838

839

840

841

842

843

844

845

846

847

848

849

850

851

(a) Results in CS1 from June to October 2017; (b) Results in different sites.

Figure 6. The RDA results of the dominant soil bacteria phyla in relation to soil physical and chemical factors

(a) Results in CS1 from June to October 2017 and (b) significance analyses; (c) Results in different sites and (d) significance analyses. The red arrows represent dominant bacterial phyla. The blue arrows represent soil chemical and physical characteristics and climate factors: SpH, MR, MT, SAN, SAP, SAK, SOM. Significant code * means $\operatorname{Pr}<0.05$ level.

\section{Figure 7. Bacterial community differences between the root tips and the rhizospheric soil}

(a) Venn diagram representation of shared OTUs across different samples or groups; (b) PCA based on OTU abundance.

Figure 8. The RDA results of bacteria functions predicted in relation to environmental factors of sample sites
(a) RDA results of all samples and (b) Significance analyses. 


\section{Table 1 (on next page)}

\section{Bacteria alpha diversity}

(a) Collection site 1 from June to October 2017.

(b) Different collection sites in August 2017. 
1

2

\begin{tabular}{ccc|crr}
\hline Samples & Shannon index & Simpson index & Samples & Shannon index & Simpson index \\
\hline CS1-G1 & 3.06 & 0.13 & CS1-T1 & 6.41 & 0.005 \\
CS1-G2 & $\mathbf{4 . 0 3}$ & $\mathbf{0 . 0 8}$ & CS1-T2 & 6.45 & 0.005 \\
CS1-G3 & 2.73 & 0.17 & $\mathbf{C S 1 - T 3}$ & $\mathbf{6 . 5 5}$ & $\mathbf{0 . 0 0 3}$ \\
CS1-G4 & 2.50 & 0.20 & CS1-T4 & 6.52 & 0.004 \\
CS1-G5 & 2.78 & 0.22 & CS1-T5 & 6.46 & 0.004 \\
\hline
\end{tabular}

3

4

5

\begin{tabular}{ccc|crr}
\hline Samples & Shannon index & Simpson index & Samples & Shannon index & Simpson index \\
\hline CS1-G & 2.73 & 0.17 & CS1-T & 6.55 & 0.003 \\
CS2-G & 3.32 & 0.13 & CS2-T & 6.44 & 0.004 \\
CS3-G & 2.96 & 0.14 & CS3-T & $\mathbf{6 . 8 1}$ & $\mathbf{0 . 0 0 2}$ \\
CS4-G & 3.27 & 0.09 & CS4-T & 5.89 & 0.009 \\
CS5-G & $\mathbf{5 . 3 9}$ & $\mathbf{0 . 0 1}$ & CS5-T & 5.89 & 0.013 \\
\hline
\end{tabular}

Table1 | Bacteria Alpha diversity.

(a) Collection site 1 from June to October. (b) Different collection sites in August.

6 


\section{Table 2 (on next page)}

Soil physical and chemical properties

(a) Collection site 1from June to October 2017.

(b) Different collection sites in August 2017. 
Table 2 | Soil physical and chemical properties.

2

(a) Collection site 1 from June to October.

\begin{tabular}{|c|c|c|c|c|c|c|c|}
\hline $\begin{array}{l}\text { Sampling } \\
\text { time at CS1 }\end{array}$ & pH & $\begin{array}{c}\text { SEN } \\
\left(\mathrm{mg} \cdot \mathrm{kg}^{-1}\right)\end{array}$ & $\begin{array}{c}\text { SAK } \\
\left(\mathrm{mg} \cdot \mathrm{kg}^{-1}\right)\end{array}$ & $\begin{array}{c}\text { SAP } \\
\left(\mathrm{mg} \cdot \mathrm{kg}^{-1}\right)\end{array}$ & $\begin{array}{c}\mathrm{SOM} \\
\left(\mathrm{g} \cdot \mathrm{kg}^{-1}\right)\end{array}$ & $\begin{array}{l}\text { MT } \\
\left({ }^{\circ} \mathrm{C}\right)\end{array}$ & $\begin{array}{c}\text { MR } \\
(\mathrm{mm})\end{array}$ \\
\hline June & $6.29 \pm 0.07$ & $182.53 \pm 6.88$ & $295.79 \pm 7.49$ & $2.12 \pm 0.15$ & $115.22 \pm 1.60$ & 17.4 & 74.8 \\
\hline July & $6.49 \pm 0.03$ & $216.63 \pm 18.61$ & $259.82 \pm 5.66$ & $2.28 \pm 0.61$ & $69.12 \pm 1.42$ & 22.7 & 172.2 \\
\hline August & $6.37 \pm 0.08$ & $247.62 \pm 28.38$ & $251.64 \pm 2.83$ & $1.21 \pm 0.27$ & $101.31 \pm 3.15$ & 23.9 & 317.0 \\
\hline September & $6.29 \pm 0.12$ & $218.01 \pm 1.79$ & $261.45 \pm 10.21$ & $3.57 \pm 1.06$ & $134.05 \pm 2.54$ & 15.0 & 78.6 \\
\hline October & $6.30 \pm 0.12$ & $214.56 \pm 5.20$ & $263.09 \pm 9.81$ & $1.52 \pm 0.79$ & $112.07 \pm 6.25$ & 7.8 & 70.2 \\
\hline
\end{tabular}

4

(b) Different collection sites in August.

\begin{tabular}{|c|c|c|c|c|c|c|c|}
\hline $\begin{array}{l}\text { Sampling } \\
\text { sites }\end{array}$ & pH & $\begin{array}{c}\text { SEN } \\
\left(\mathrm{mg} \cdot \mathrm{kg}^{-1}\right)\end{array}$ & $\begin{array}{c}\text { SAK } \\
\left(\mathrm{mg} \cdot \mathrm{kg}^{-1}\right)\end{array}$ & $\begin{array}{c}\text { SAP } \\
\left(\mathrm{mg} \cdot \mathrm{kg}^{-1}\right)\end{array}$ & $\begin{array}{c}\text { SOM } \\
\left(\mathrm{g} \cdot \mathrm{kg}^{-1}\right)\end{array}$ & $\begin{array}{l}\text { MT } \\
\left({ }^{\circ} \mathrm{C}\right)\end{array}$ & $\begin{array}{c}\text { MR } \\
(\mathrm{mm})\end{array}$ \\
\hline $\mathrm{CS} 1$ & $6.37 \pm 0.08$ & $247.62 \pm 28.38$ & $251.64 \pm 2.83$ & $1.21 \pm 0.27$ & $101.30 \pm 3.15$ & 23.90 & 317.00 \\
\hline $\mathrm{CS} 2$ & $6.14 \pm 0.05$ & $230.06 \pm 4.30$ & $281.08 \pm 7.49$ & $7.77 \pm 0.23$ & $118.12 \pm 3.12$ & 21.40 & 373.80 \\
\hline $\mathrm{CS} 3$ & $6.88 \pm 0.29$ & $231.78 \pm 4.66$ & $181.33 \pm 7.49$ & $8.50 \pm 3.92$ & $138.42 \pm 8.36$ & 21.30 & 336.90 \\
\hline CS4 & $5.40 \pm 0.17$ & $372.99 \pm 10.93$ & $498.57 \pm 4.91$ & $6.98 \pm 1.83$ & $230.53 \pm 4.91$ & 19.60 & 297.40 \\
\hline CS5 & $5.66 \pm 0.26$ & $321.67 \pm 4.66$ & $303.97 \pm 2.83$ & $8.04 \pm 1.39$ & $185.39 \pm 3.71$ & 18.40 & 186.00 \\
\hline
\end{tabular}

Note: The physical and chemical properties of soil were represented by the mean $\pm \mathrm{SD}, \mathrm{n}$ value $=3$. 
Figure 1

Shannon index boxplot of bacterial communities between the rhizospheric soil and the root tips. 


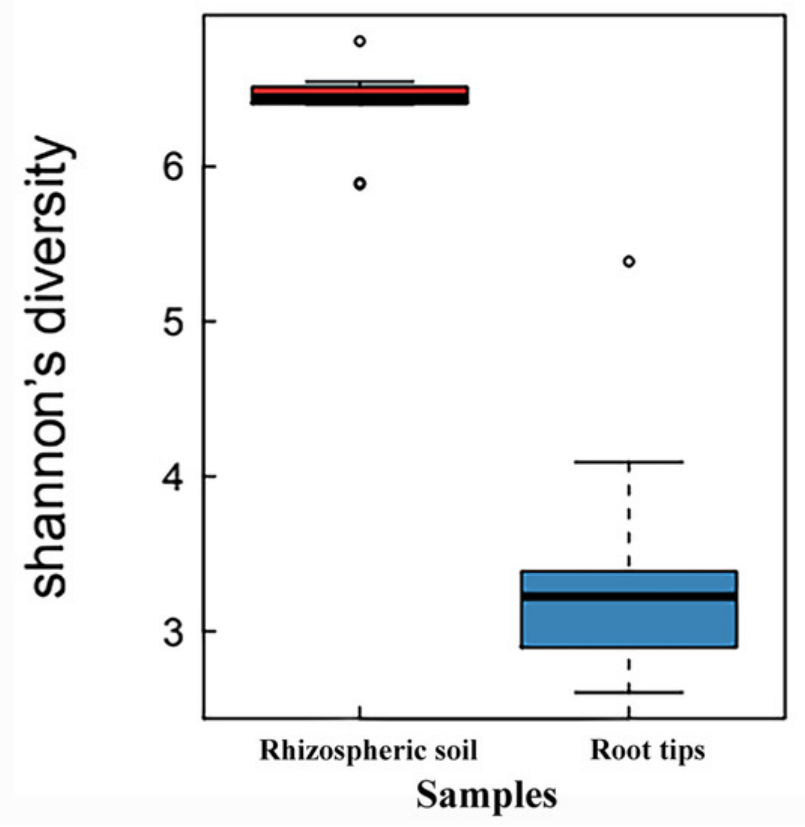

Peer] reviewing PDF | (2021:06:62999:3:0:NEW 29 Jan 2022) 
Figure 2

Beta diversity responded to the bacterial community of the rhizospheric soil and the root tips.

(a) Principal coordinates analysis (PCoA) based on Bray-Curits distance $(P<0.001$, permutational multivariate analysis of variance (PERMANOVA) by Adonis); (b) heat map based on bray-Curtis distance. 


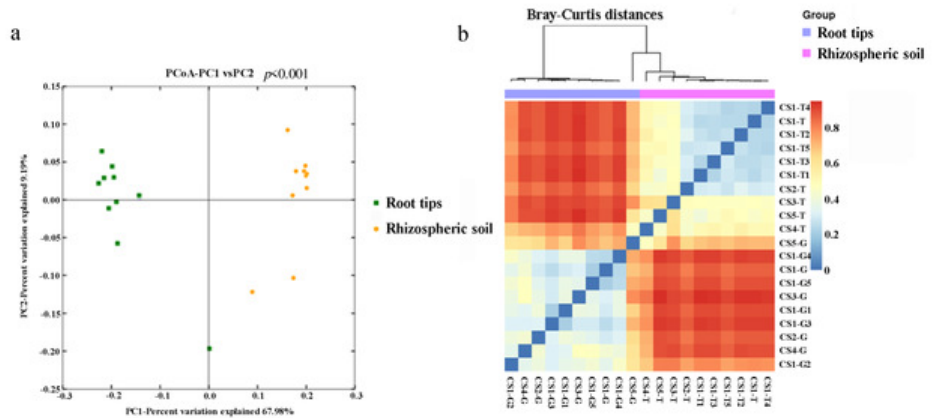




\section{Figure 3}

The bacterial composition of the rhizospheric soil and the root tips based on taxonomic OTUs richness

(a) Log-scaled percentage heat map of Phylum-level; (b) The bacterial dominant Phyla in different collection sites (the relative richness $>0.01 \%$ ); (c) The biomarker in root tips and in rhizospheric soil of Korean pine forest by LEfSe.

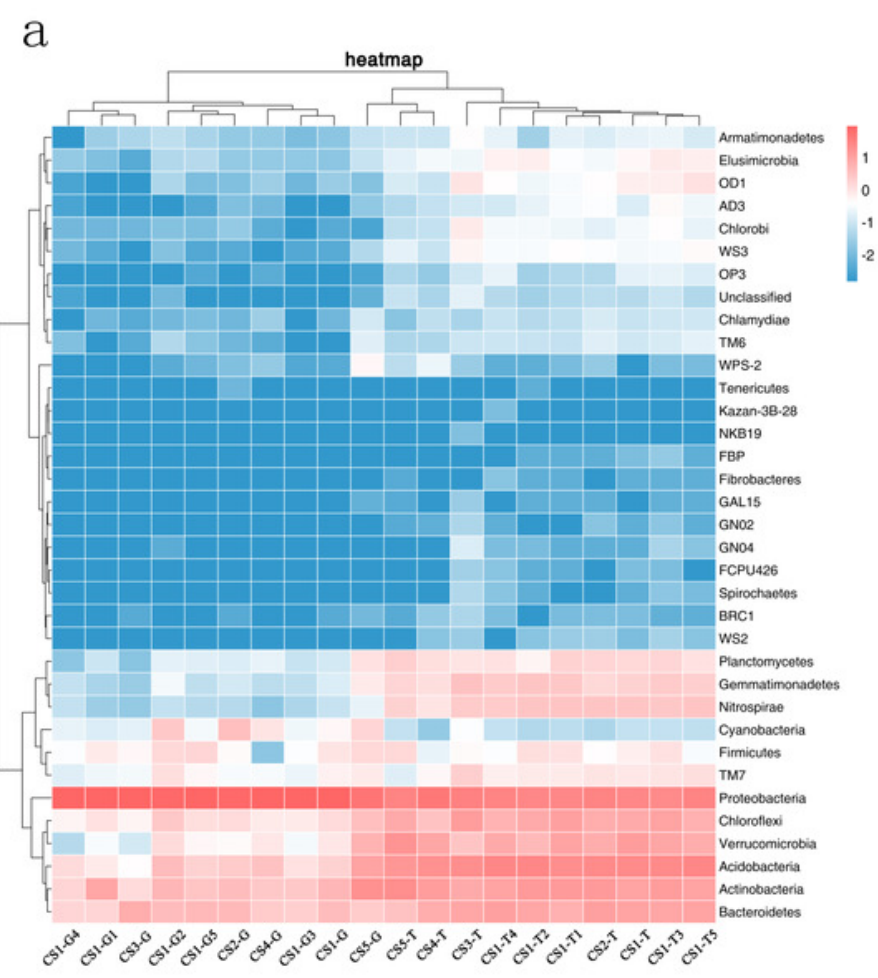

$\mathrm{b}$

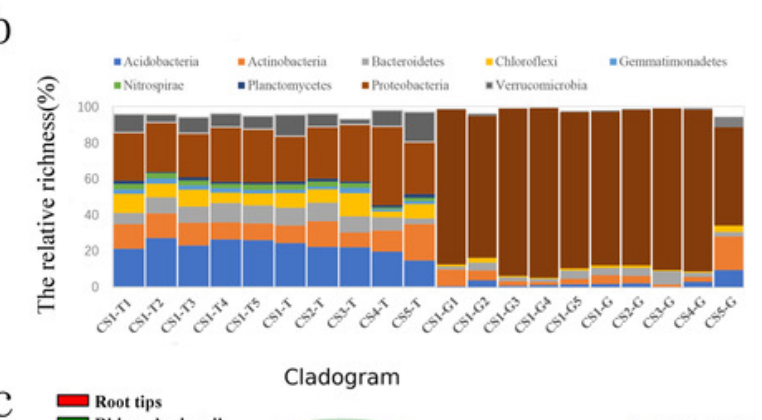

C $\underbrace{}_{\text {Rhizospheric soil }}$

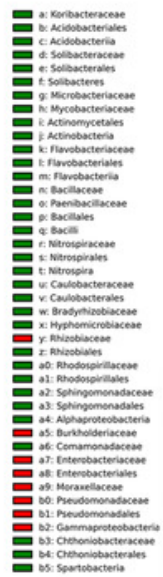


Figure 4

Log-scaled percentage heatmap of bacterial functions predicted in different samples. 


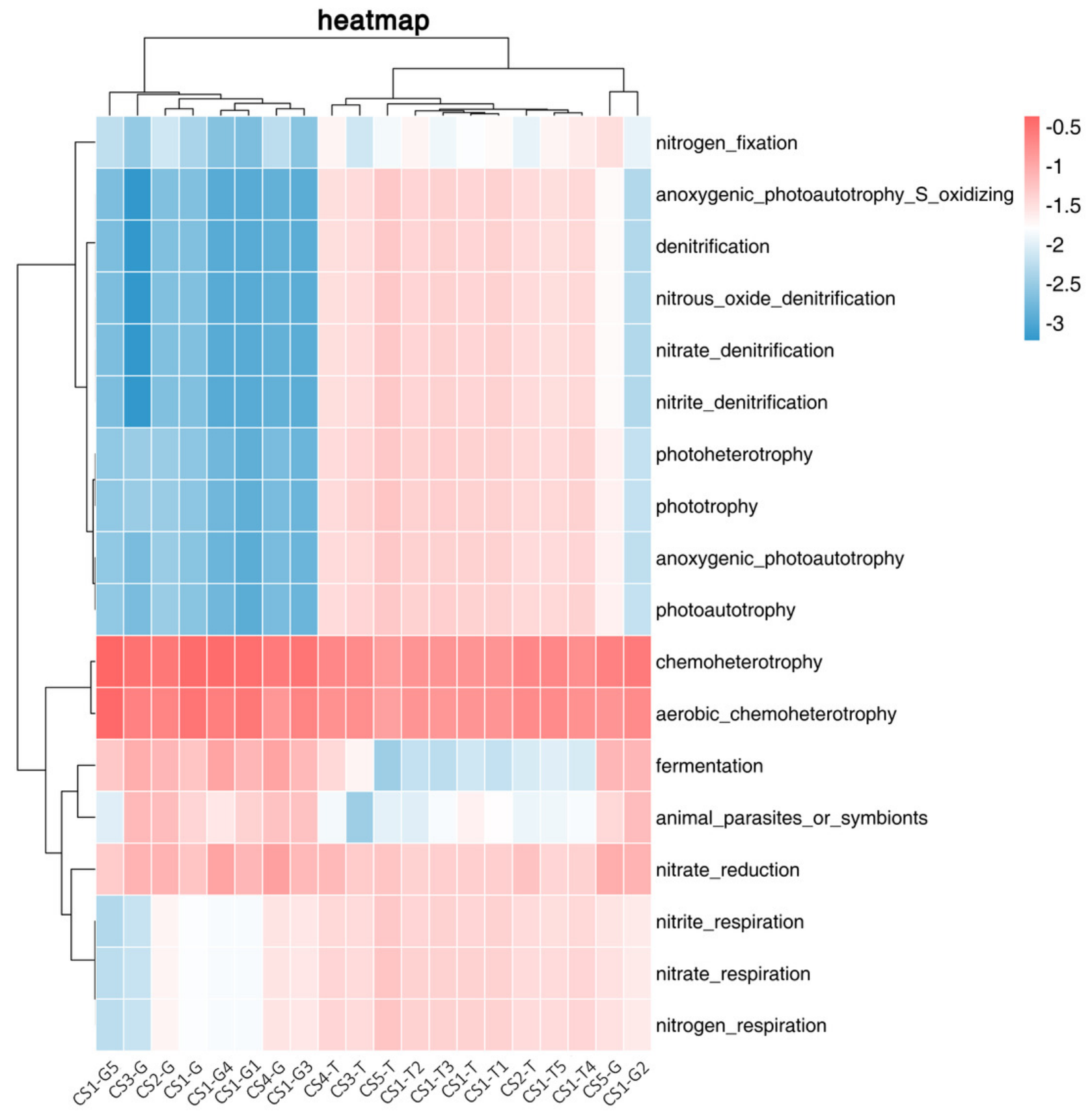


Figure 5

Heatmap showed the correlation of soil physical and chemical properties

(a) Results in CS1 from June to October; (b) Results in different sites. 


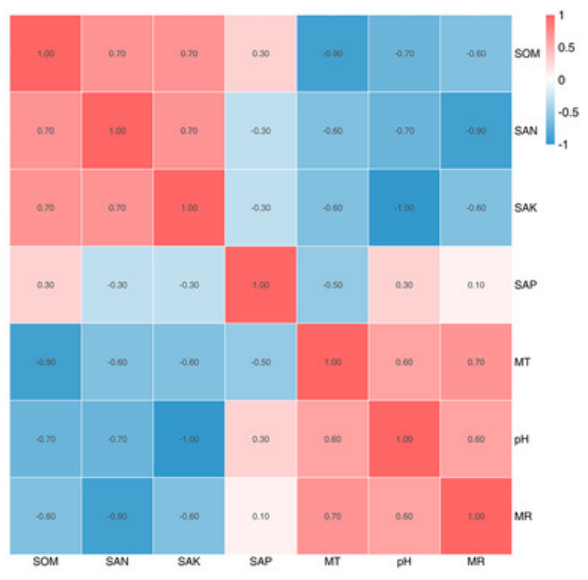

a

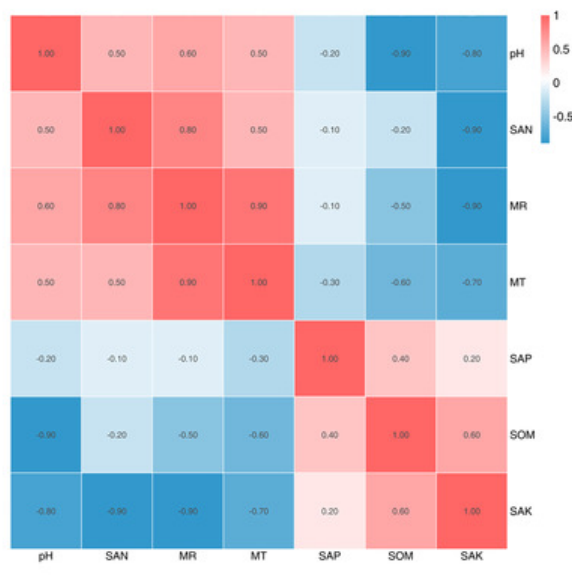

b 


\section{Figure 6}

The RDA results of the dominant soil bacteria phyla in relation to soil physical and chemical factors

(a) Results in CS1 from June to October 2017 and (b) significance analyses; (c) Results in different sites and (d) significance analyses. The red arrows represent dominant bacterial phyla. The blue arrows represent soil chemical and physical characteristics and climate factors: SpH, MR, MT, SAN, SAP, SAK, SOM. Significant code * means $\operatorname{Pr}<0.05$ level. 
a

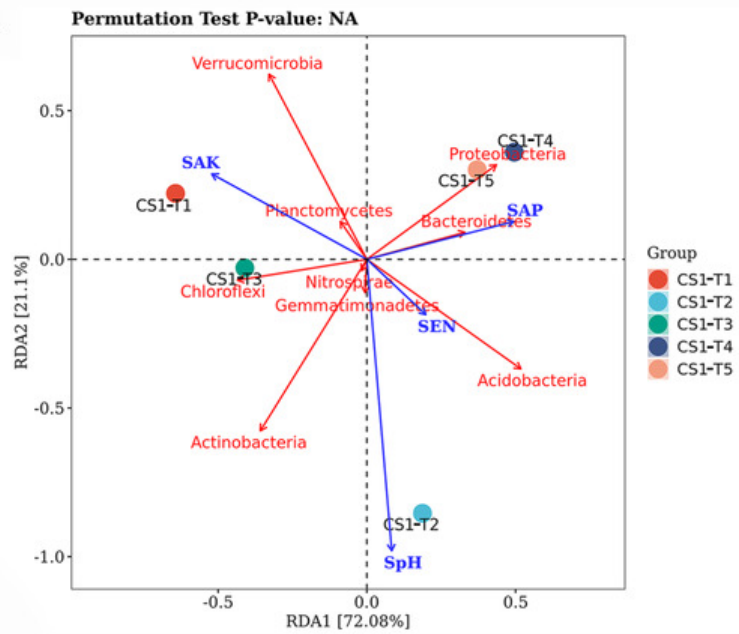

c

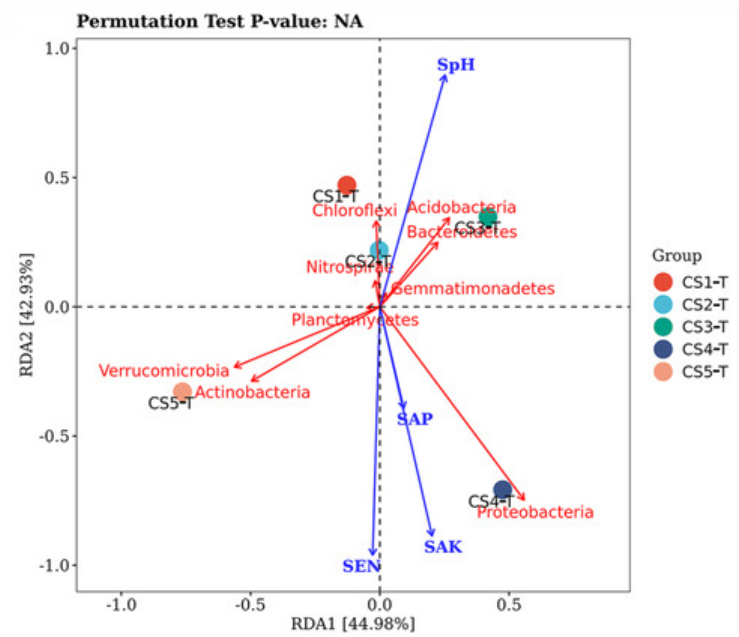

b

\begin{tabular}{lcc}
\hline & $\mathrm{r}^{2}$ & $\operatorname{Pr}(>\mathrm{r})$ \\
\hline $\mathrm{SpH}$ & 0.97 & 0.03 \\
SOM & 0.92 & 0.08 \\
MT & 0.67 & 0.36 \\
SAK & 0.35 & 0.63 \\
MR & 0.32 & 0.67 \\
SAP & 0.26 & 0.73 \\
SEN & 0.07 & 0.83 \\
\hline
\end{tabular}

d

\begin{tabular}{lcc}
\hline & $\mathrm{r}^{2}$ & $\operatorname{Pr}(>\mathrm{r})$ \\
\hline SOM & 0.96 & 0.03 \\
SpH & 0.87 & 0.10 \\
SEN & 0.92 & 0.10 \\
SAK & 0.83 & 0.18 \\
MR & 0.78 & 0.21 \\
MT & 0.73 & 0.32 \\
SAP & 0.16 & 0.78 \\
\hline
\end{tabular}




\section{Figure 7}

Bacterial community differences between the root tips and the rhizospheric soil

(a) Venn diagram representation of shared OTUs across different samples or groups; (b) PCA based on OTUs abundance.

a

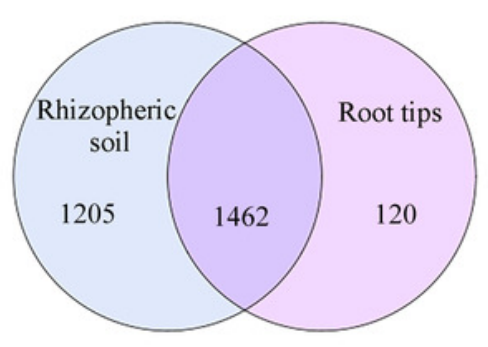

b

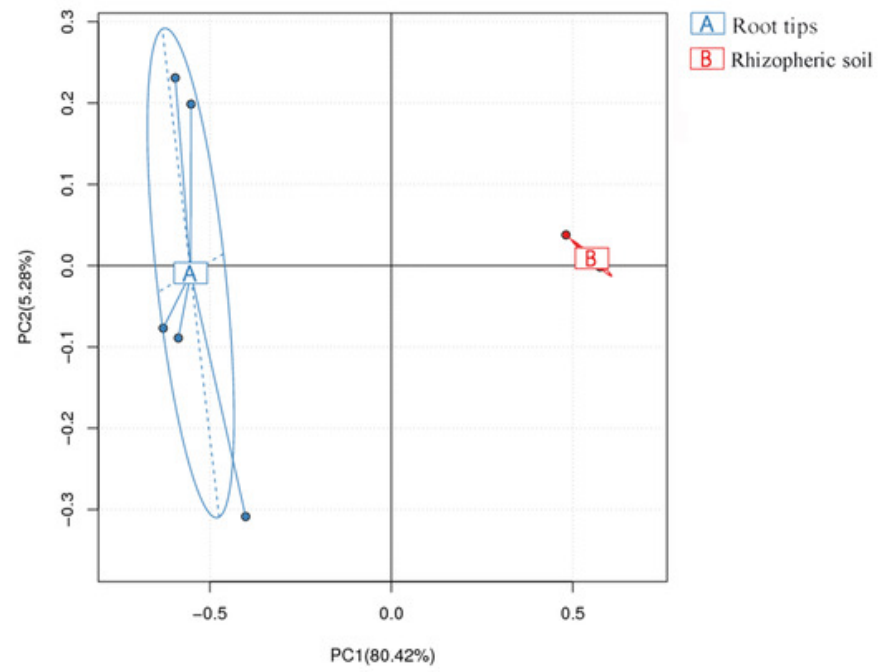


Figure 8

The RDA results of bacteria functions predicted in relation to environmental factors of sample sites

(a) RDA results of all samples and (b) Significance analyses. 


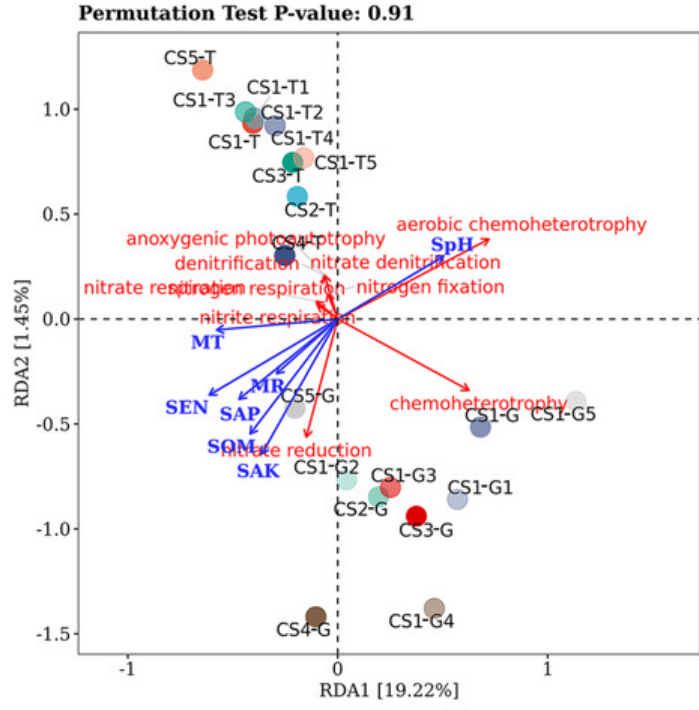

$a^{\prime}$

\begin{tabular}{lcc}
\hline & $\mathrm{r}^{2}$ & $\operatorname{Pr}(>\mathrm{r})$ \\
\hline SEN & 0.29 & 0.04 \\
SOM & 0.21 & 0.14 \\
SAK & 0.20 & 0.15 \\
SAP & 0.19 & 0.16 \\
SpH & 0.19 & 0.17 \\
MT & 0.18 & 0.17 \\
MR & 0.08 & 0.50 \\
\hline
\end{tabular}

b 